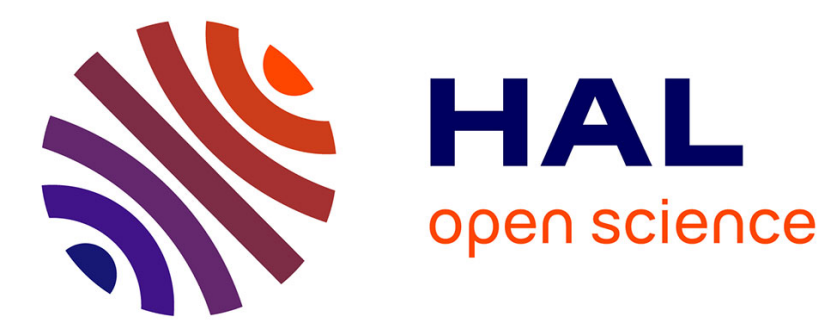

\title{
New Leptogamasus mite species (Parasitiformes: Parasitidae) from Europe. III. Northern and Central Italy Wojciech Witaliński
}

\section{> To cite this version:}

Wojciech Witaliński. New Leptogamasus mite species (Parasitiformes: Parasitidae) from Europe. III. Northern and Central Italy. Acarologia, 2021, 61 (3), pp.664-699. 10.24349/DQzL-I4Kh . hal03355655

\section{HAL Id: hal-03355655 \\ https://hal.science/hal-03355655}

Submitted on 27 Sep 2021

HAL is a multi-disciplinary open access archive for the deposit and dissemination of scientific research documents, whether they are published or not. The documents may come from teaching and research institutions in France or abroad, or from public or private research centers.
L'archive ouverte pluridisciplinaire HAL, est destinée au dépôt et à la diffusion de documents scientifiques de niveau recherche, publiés ou non, émanant des établissements d'enseignement et de recherche français ou étrangers, des laboratoires publics ou privés.

\section{(c)(1)}

Distributed under a Creative Commons Attribution| 4.0 International License 


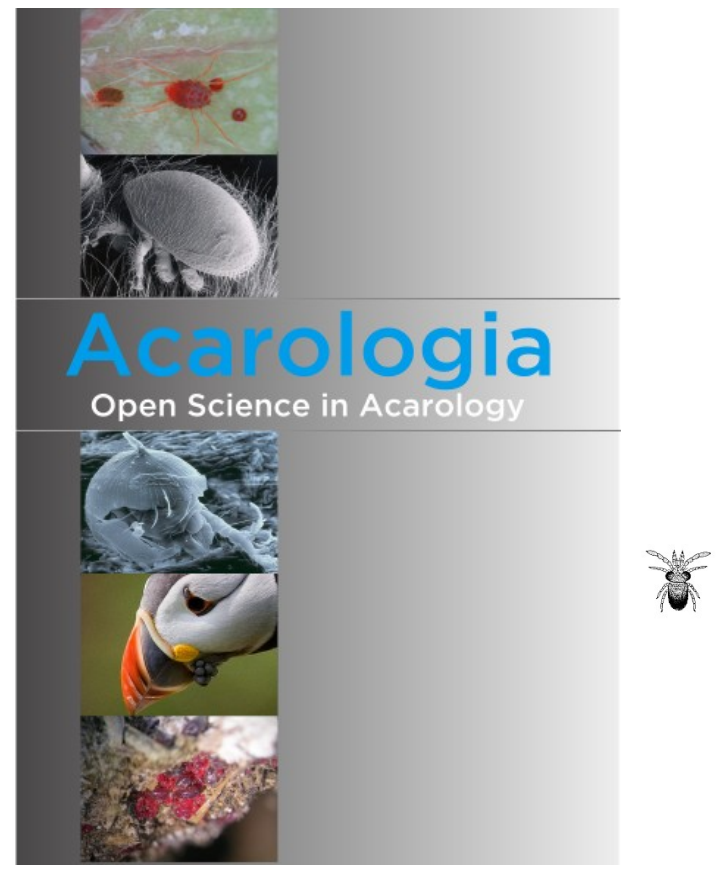

\section{Acarologia}

A quarterly journal of acarology, since 1959

Publishing on all aspects of the Acari

All information:

http://www1.montpellier.inra.fr/CBGP/acarologia/

acarologia-contact@supagro.fr

\section{OPEN ACCESS}

\section{Acarologia is proudly non-profit, with no page charges and free open access}

Please help us maintain this system by encouraging your institutes to subscribe to the print version of the journal and by sending us your high quality research on the Acari.

Subscriptions: Year 2021 (Volume 61): $450 €$ http://www1.montpellier.inra.fr/CBGP/acarologia/subscribe.php

Previous volumes (2010-2020): $250 €$ / year (4 issues)

Acarologia, CBGP, CS 30016, 34988 MONTFERRIER-sur-LEZ Cedex, France

ISSN 0044-586X (print), ISSN 2107-7207 (electronic)

The digitalization of Acarologia papers prior to 2000 was supported by Agropolis Fondation under the reference ID 1500-024 through the «Investissements d'avenir » programme

(Labex Agro: ANR-10-LABX-0001-01)
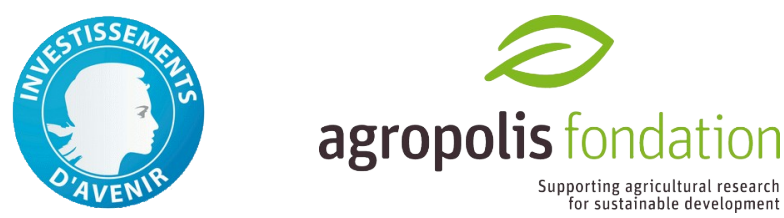

Acarologia is under free license and distributed under the terms of the Creative Commons-BY. 


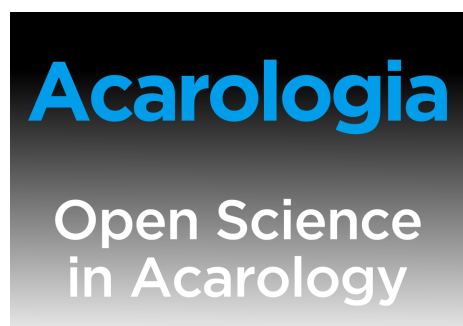

New Leptogamasus mite species (Parasitiformes: Parasitidae) from Europe. III. Northern and Central Italy

\author{
Wojciech Witaliński ${ }^{a}$ \\ ${ }^{a}$ Department of Comparative Anatomy, Institute of Zoology and Biomedical Research, Jagiellonian \\ University, Gronostajowa 9, 30-387 Kraków, Poland.
}

\section{Original research}

\section{ABSTRACT}

This paper describes five new species of mites in the family Parasitidae from Italy, namely, Leptogamasus (Leptogamasus) bucerus n. sp., Leptogamasus (L.) cortinis n. sp., Leptogamasus (L.) silvestris $\mathbf{n}$. sp. and Leptogamasus (L.) parasilvestris $\mathbf{n}$. sp. from northern Italy, and Leptogamasus (L.) monteamiatus n. sp. from Tuscany.

Keywords Leptogamasus subgenus; mite taxonomy; new species; northern and central Italy; Tuscany fauna

Zoobank http://zoobank.org/9D7876F8-AEAA-432D-9DBE-84B6A486FF75

\section{Introduction}

Mites belonging to the genus Leptogamasus Trägårdh, 1936 and subgenus Leptogamasus s. str. are commonly found in forest litter in Europe. Their general features have been outlined in previous papers (Witaliński, 2019; Witaliński, 2020), and new species were recently described from northern Italy (Witaliński, 2021). At least 12 new species are present in collections, and they will be described in a series of papers discussing the species from Romania, Karawanki Mts, and Austria, as well as from two areas in Italy, i.e. Tuscany (Vallombrosa) and Sardinia. In the present study, the following four Leptogamasus (Leptogamasus) species from northern Italy are described, as well as one new species from Tuscany. The main features of these species are the same as in the other members of Leptogamasus Trägårdh, 1936 s. str. subgenus (Witaliński, 2021).

\section{Materials and Methods}

The methods applied in the present study were described in detail in the previous paper in this series (Witaliński, 2020). The structure of the podonotum in these species is very uniform, so it is not described in detail for every species. The studied material was collected by the author, otherwise indicated.

\section{Systematics}

\section{Family Parasitidae}

\section{Genus Leptogamasus Trägårdh, 1936 sensu Juvara-Balş, 1981}

Type species Leptogamasus suecicus Trägårdh, 1936: 227.

Some taxonomic remarks on the genus were provided recently (Witaliński, 2021).

Copyright Witaliński W.

Distributed under 


\section{Leptogamasus (Leptogamasus) Trägårdh, 1936.}

Type species Leptogamasus suecicus Trägårdh, 1936: 227.

Leptogamasus (Leptogamasus) bucerus n. sp.

Zoobank: C083DCE3-619E-4E63-93DF-AC18B6137BB7

(Figures 1-5)

\section{Diagnosis}

Female and male. Gnathotectum trispinate with similar pointed prongs, the central one somewhat longer; gland pore $g v 1$ present; podonotum with 21 pairs of setae, opisthonotum with the normal 24 pairs of setae plus one supplementary pair, in some specimens one seta of the $\mathrm{S}$ and/or R series may be missing; Tr IV without tubercle.

Female. All three prongs of gnathotectum similarly narrow, central one slightly longer; presternal plates irregular and distant, with axially directed protrusions; anterior margin of the sternal shield with a shallow concavity between setae st 1 ; gland pores $g v 1$ close to the body axial line; epigynial shield with two prominent teeth on the internal (dorsal) surface, anterior margins wavy, posterolateral margins short and arcuate; spherules of the endogynium elongated and pointed anteriorly, lateral walls of endogynial sac with two pairs of teeth, stipule large and bifid, with several small teeth and a richly dentate basal part.

Male. Gnathotectum prongs subtriangular and shorter than in the female; genital lamina with rounded anterior corners; presternal plates subrectangular with anterior protrusions; corniculi with sinuous adaxial margin; cheliceral fixed digit nearly straight, with a wider blunt apex and elevation on the external (dorsal) margin, internal (ventral) margin edentate, only the lamellar low and irregular tooth-like protrusion in front of pilus dentilis is present; tibia II with a distal tubercle on the anterolateral surface, femur II axillary process half-moon shaped, spurs on the genu and the tibia conical, located some distance away from the distal article margin, the one on the tibia slightly longer.

\section{Description}

Female (Figures 1-3)

Idiosoma. Moderately sclerotised, 580-620 x 340-360 (length x width, $\mathrm{n}=5$ ), holotype $592 \times 351$. Podonotum with 21 pairs of setae, setae length: 25-30 (j1), 26-33 (j2), 33-39 (j3), 35-39 (j4), 31-35 (j5), 27-30 (j6), 78-86 (r3), in holotype 26 (j1), 35 (j2), 39 (j3), 39 (j4), 33 (j5), 27 (j6), 85 (r3). Opisthonotum (Fig. 1) with 24 pairs of setae plus one pair of supplementary setae (Fig. 1A), in some specimens one seta of S and/or R series may be missing (Fig. 1B). Setae relatively short, length 24-27, holotype 24-29. Dorsal setae simple, reticulation of the podonotum not discernible, opisthonotum with a scale-like reticulation. Peritreme length 150-154, including stigma (holotype 154), anterior tip located anteriorly to the mid-level of Co II, at the level between the podonotal setae $r 2$ and $z 2$.

Ventral idiosoma. Setae length: 39-44 (st1), 43-47 (st2), 39-46 (st3), 38-43 (st4), 34-38 (st5), 39-46 (JV1), 25-30 (ZV1), other opisthogastric setae ca. 26-37, in holotype 47 (st1), 48 (st2), 47 (st3), 43 (st4), 40 (st5), 43 (JV1), 29 (ZV1), other opisthogastric setae ca. 24-39. Ventral setae simple, reticulation of the sternum and opisthogaster scale-like. Anterior margin of the sternal shield slightly concave (Fig. 2), the area between the presternal plates and the sternum margin usually with transverse lines. Presternal plates distant and of irregular shape, with long adaxial protrusions. The pores $g v 1$ located axially close one to another. Paragynial shields (Figs 2, 3B) - metagynial sclerites narrow and arcuate, epigynial shield (Figs 2, 3A) with two prominent teeth on the internal (dorsal) surface. The anterior epigynial margins wavy and bearing two minute denticles, posterolateral margins short and convex, and the posterior margin straight. Epigynial apex not pigmented (Fig. 3A). Endogynium (Figs 2, 3C-F) large, with spherules elongated and pointed anteriorly, endogynial sac narrow, its lateral walls with two pairs of axially directed teeth (Fig. 3F), stipule large and bifid, with several small teeth and 


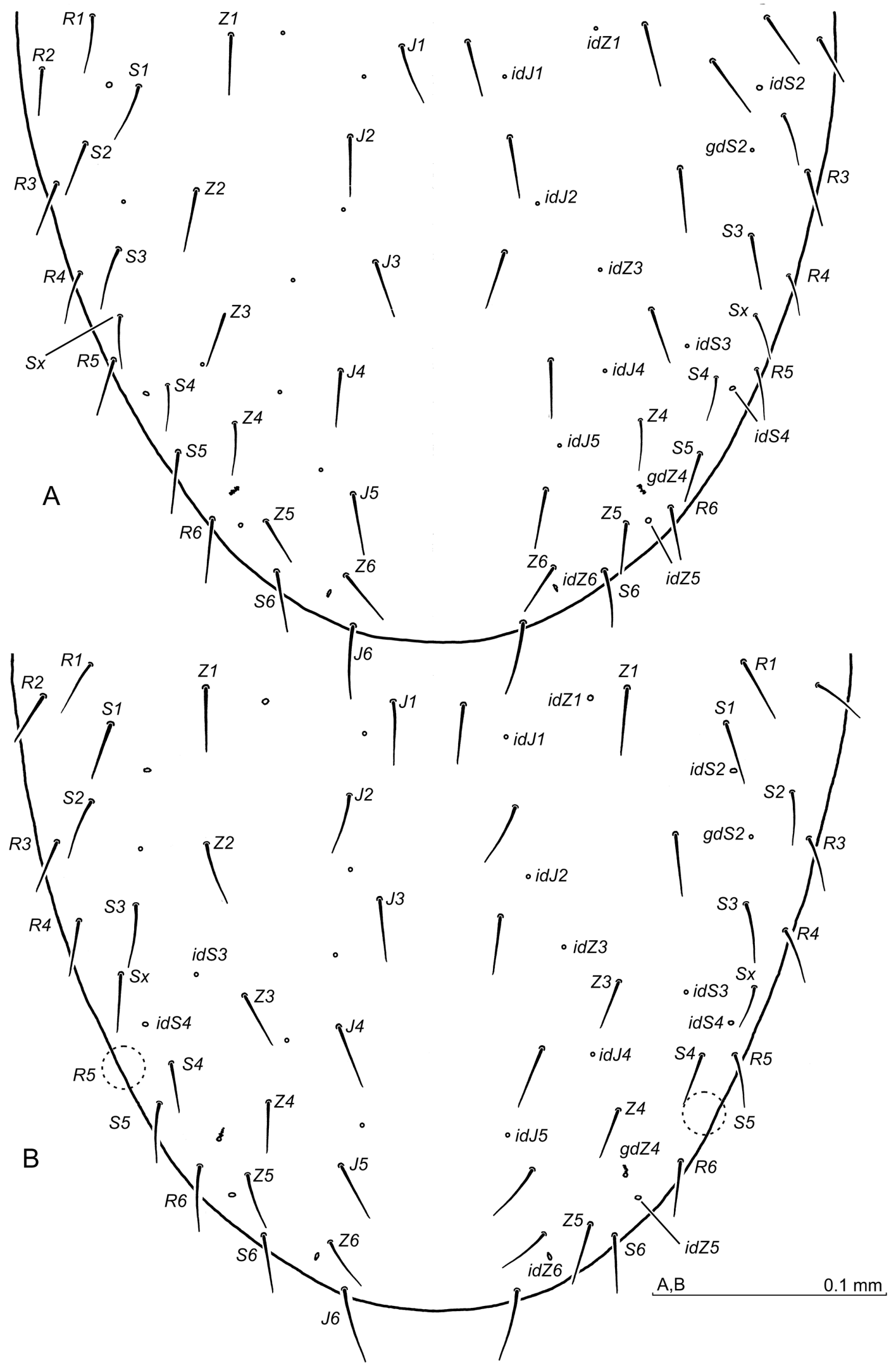

Figure 1 Leptogamasus (L.) bucerus $\mathbf{n}$. sp., opisthonotum of the female, two aspects (A, B). setae (J, Z, $S, R)$, supplementary setae $S x$, pores $(i d J, i d Z, i d S)$, and gland openings ( $g d S$, gdZ) are marked. Rings (in a dashed line) indicate where the relevant setae are missing. 


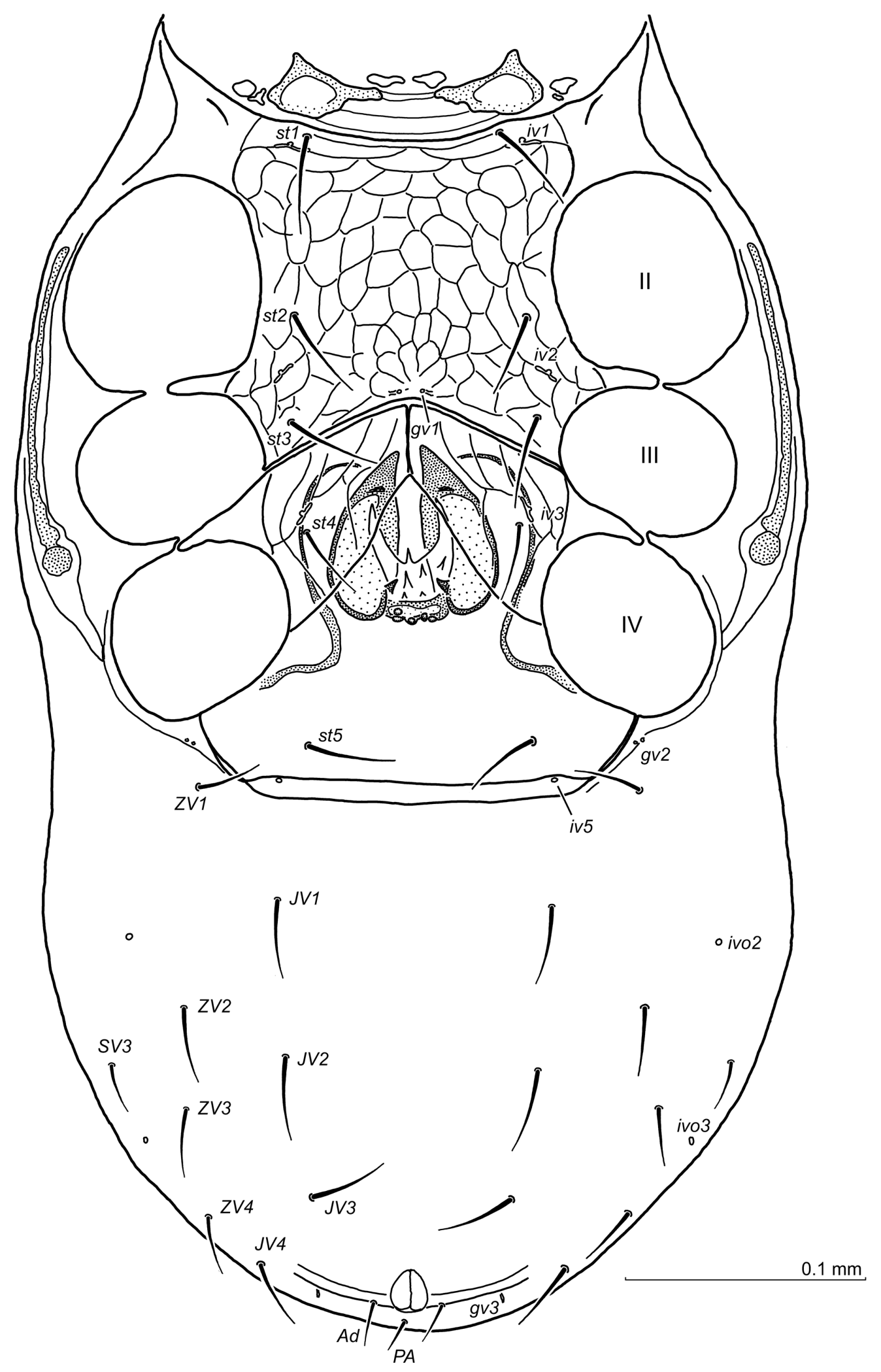

Figure 2 Leptogamasus (L.) bucerus n. sp., ventral side of the female idiosoma. Reticulation of the sternum and the paragynia is shown Abbreviations: II-IV the openings for coxae II to IV; $A d$ and PA adanal and postanal setae, respectively; gv1-gv3 gland openings; st $1-s t 5$ sternal setae; $J V, Z V$ and $S V$ series of opisthogastric setae; iv1-iv3, iv5, ivo2, ivo3 pore openings. 

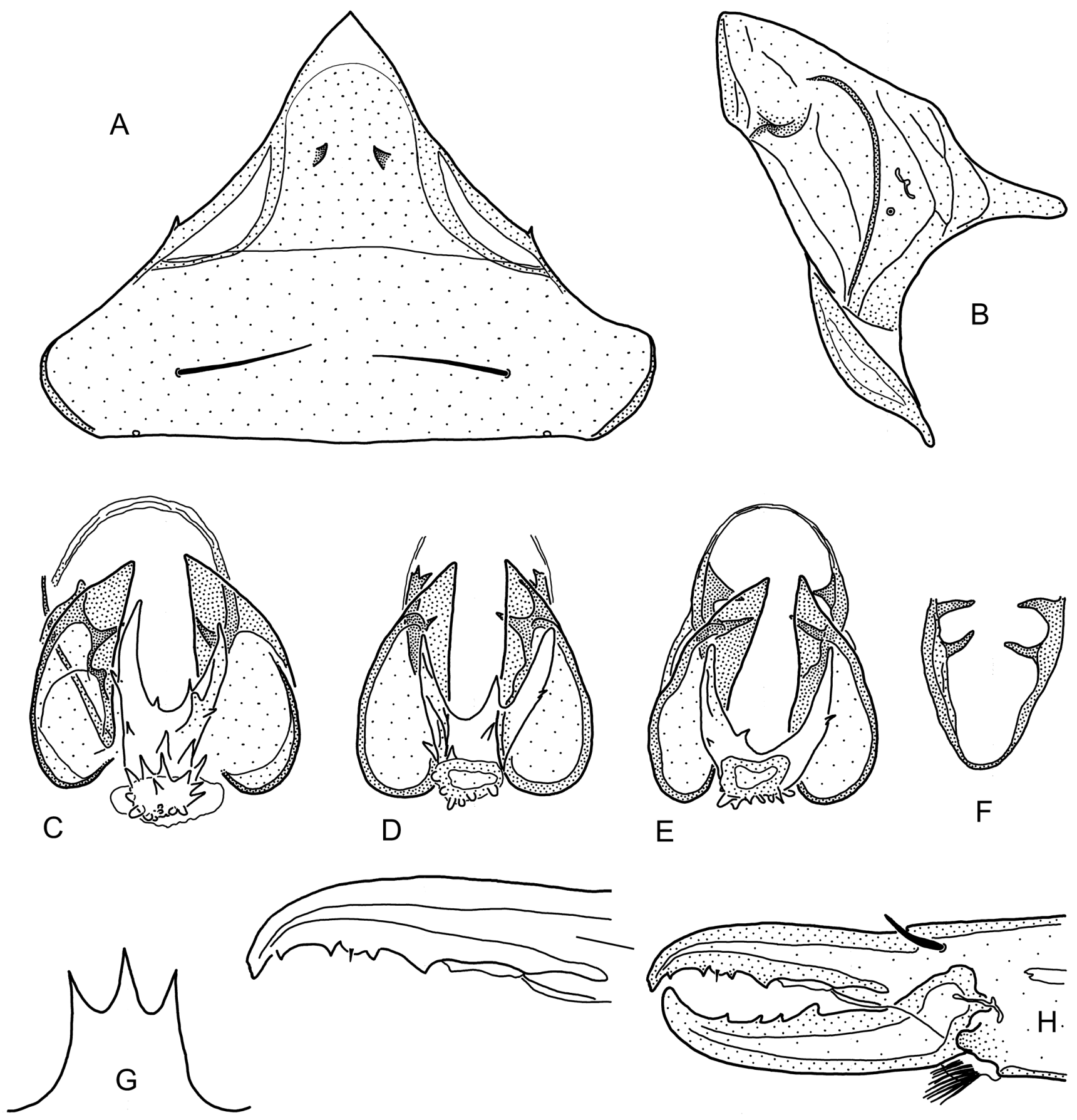

Figure 3 Leptogamasus (L.) bucerus $\mathbf{n}$. sp., female: A - epigynium; B - paragynium; C-E - endogynium, different aspects; F - walls of endogynial sac; $\mathrm{G}$ - gnathotectum; H - chelicera, antiaxially. E - holotype. 
a basal part richly dentate (Fig. 3C). Gland pores gv2 with two openings; iv5, ivo2, ivo3 and gv3 clearly visible.

Gnathosoma. Gnathotectum (Fig. 3G) trispinate, with pointed, similarly narrow and moderately long prongs, the central one somewhat longer. Corniculi conical, hypostome with 11 rows of denticles, hypostomal and palpcoxal setae simple. Palptrochanter seta $v 1$ simple, $v 2$ barbed. Chelicera (Fig. 3H) - movable digit with four teeth, the proximal one larger. Fixed digit with two distant teeth in front of pilus dentilis and two behind it, followed by a lamellar edge.

Legs. Setae all, al2 on Fe II short and thick, the anteroventral seta enlarged and barbed. Ti II with thickened and barbed ventral setae. Leg IV: posterodorsal and posterolateral setae on the femur thick and short, posteroventral seta on the tibia thickened and barbed. Some ventral and posterolateral setae on the tarsus, as well as the posteroventral seta on the basitarsus, thickened and terminally barbed. Tr IV without the dorsal tubercle. Other aspects of legs I-IV unremarkable.

Male (Figures 4, 5)

Idiosoma. Sclerotised as in the female, 550-580 x 310-325 $\mu \mathrm{m}$ (length $\mathrm{x}$ width, $\mathrm{n}=5$ ). Podonotum - length of setae: 31-39 (j1), 27-35 (j2), 31-35 (j3), 33-37 (j4), 24-26 (j5), 21-26 (j6), 80-89 (r3). Opisthonotum setae length from ca. 20 to 25 . Peritreme including stigma 148-150 long, ending anteriorly as in the females. Dorsal setae simple, reticulation pattern as in the female.

Ventral idiosoma. Setae length: 34-39 (st1), 37-42 (st2), 32-34 (st3), 30-33 (st4), 30-33 (st5), 35-37 (JV1), 20-22 (ZV1), other opisthogastric setae ca. 24-34. Ventral setae simple.

Sternal region (Fig. 4A) - genital lamina (Fig. 4A,B) with rounded anterior corners, presternal plates subrectangular with anterior protrusions. Sternum (Fig. 4A) with gland pores gv1 slightly anterior to the st 3 setae level, followed by two elongated and two button-like thickenings of the sternal cuticle, the latter located somewhat laterally at the level between $i v 3$ sternal pores. Pores $g v 2$ with two openings, pores $i v 5$ equally distant from setae st 5 and $Z V 1$, but slightly shifted adaxially. Sternum and opisthogaster reticulation scale-like.

Gnathosoma. Gnathotectum (Fig. 4C) prongs similar and shorter than in the female. Corniculi (Fig. 4D) adaxial margin sinuous, hypostome with 13 rows of denticles, hypostomal setae simple, palpcoxal setae barbed and slightly larger than hypostomals. Palptrochanter seta $v 1$ simple, $v 2$ larger and barbed. Chelicera (Fig. 4E,F) - movable digit (Fig. 4F) with one tooth followed by a semicircular edge proximally, fixed digit nearly straight, blunt and widened apically, and with an arcuate elevation of the external (dorsal) margin. Teeth absent except for the lamellar minute tooth-like protrusion between pilus dentilis and the apex of digit.

Legs. Ventral seta $v 1$ of Tr I simple, seta $v 2$ barbed. Tibia II shows a characteristic distal tubercle on the anterolateral surface. Leg II is spurred as follows: when observed from the ventral side (Fig. 5A), femoral main spur is finger-shaped, axillary process hooked and directed posterolaterally, genual spur is oriented obliquely to the article axis, the tibial spur is oriented axially. When viewed from the lateral side, leg II (Fig. 5B) shows finger-like femoral main spur, axillary process half-moon shaped, and spurs on the genu and tibia conical, located at some distance from the distal article margin. Tibial spur is somewhat longer than the genual one. Most of setae on leg II are simple, but setae all and al 2 on tibia and $p v 1$ on the genu are barbed. Anterolateral setae on basitarsus and tarsus thickened and finely barbed. Setae al2 and $a d 2$ on the femur shorter and thicker, seta all thickened, ad3 needle-like. Leg IV setation as in the female. Tubercle on Tr IV absent. Other aspects of legs I-IV unremarkable.

\section{Material examined}

Holotype. Female (slide no. 1819), Cansiglio Forest (Bosco di Cansiglio), Veneto, northern Italy, $46.0482^{\circ} \mathrm{N}, 12.3971^{\circ} \mathrm{E}$, alt. ca. $1090 \mathrm{~m}$ a.s.1., 29 July 2003 , moss on the rocks in the beech forest, leg. M. Skorupski. Paratypes. 4 females (slides no. $981 \mathrm{H}-\mathrm{J}$ ), Cansiglio Forest, 13 Oct. 1984, beech forest litter, leg. by Prof. R. Dallai and the staff of the Dept. of Evolutionary Biology, University of Siena, Italy; 2 females, 4 males (slide 1740), Cansiglio Forest, 29 July 

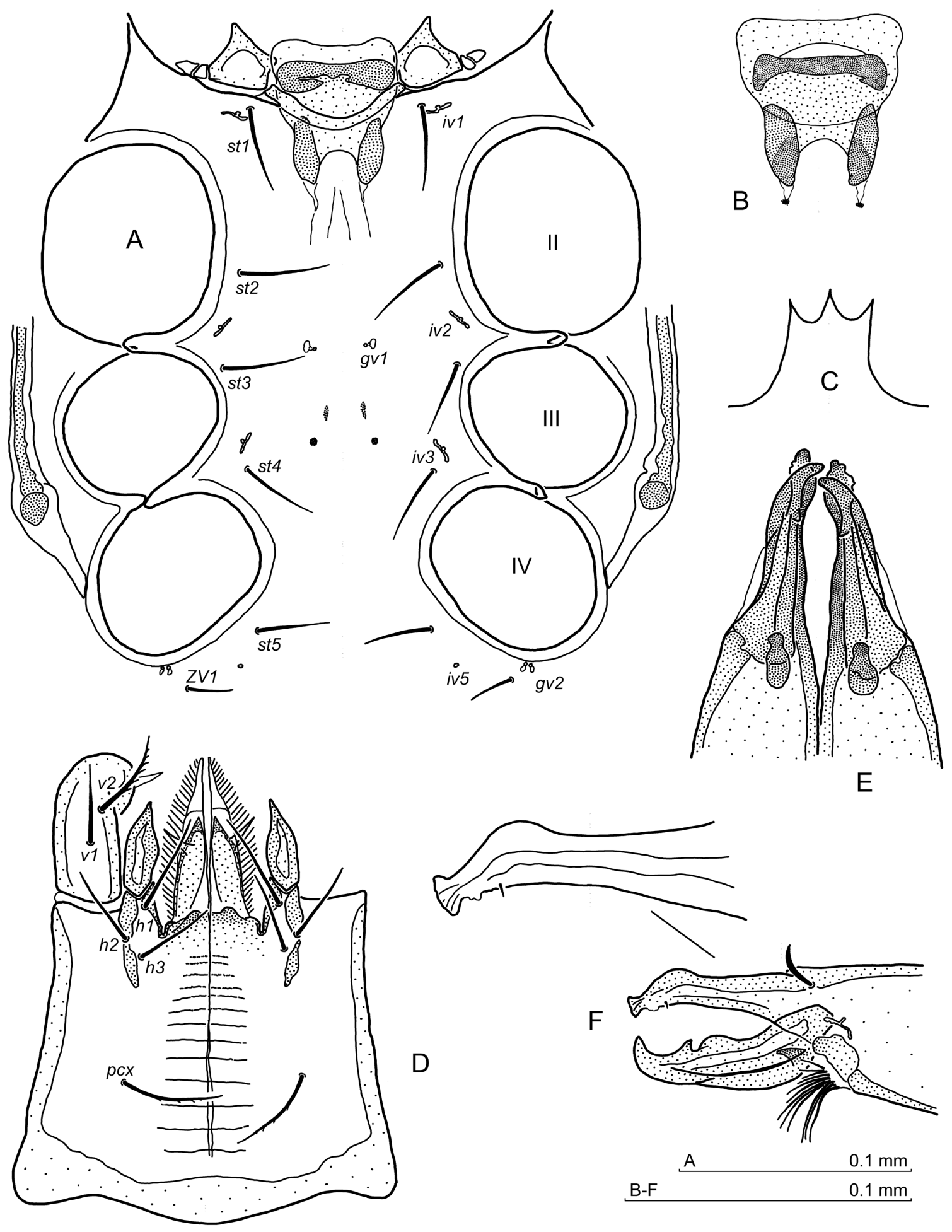

$\mathrm{E}$

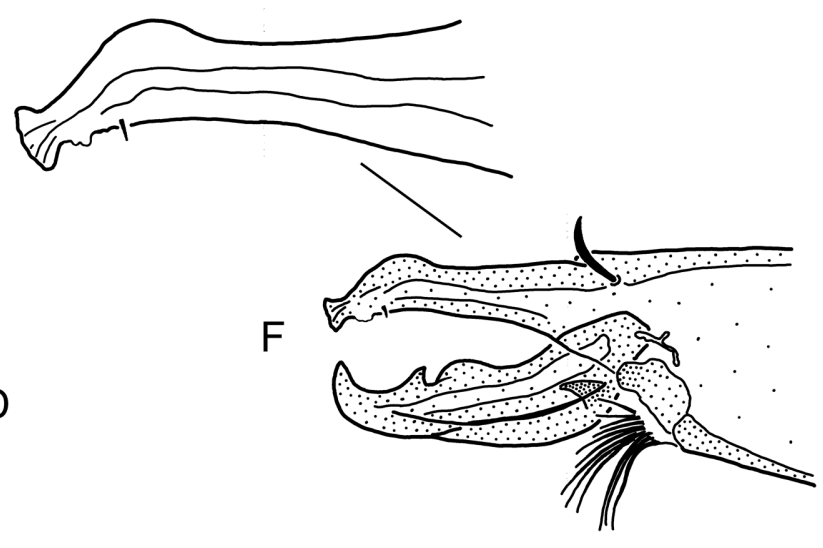

\begin{tabular}{ll} 
B $-\mathrm{A}$ & $0.1 \mathrm{~mm}$ \\
\hline
\end{tabular}

Figure 4 Leptogamasus (L.) bucerus n. sp., male: A - presternal plates, genital lamina and sternogenital shield; B - genital lamina; C gnathotectum; D - gnathosoma, ventrally; E - chelicerae, ventrally; F - chelicera, antiaxially. Abbreviations as in Figure $2, h 1-h 3$ and $p c x$ -hypostomal and palpcoxal setae, respectively. 

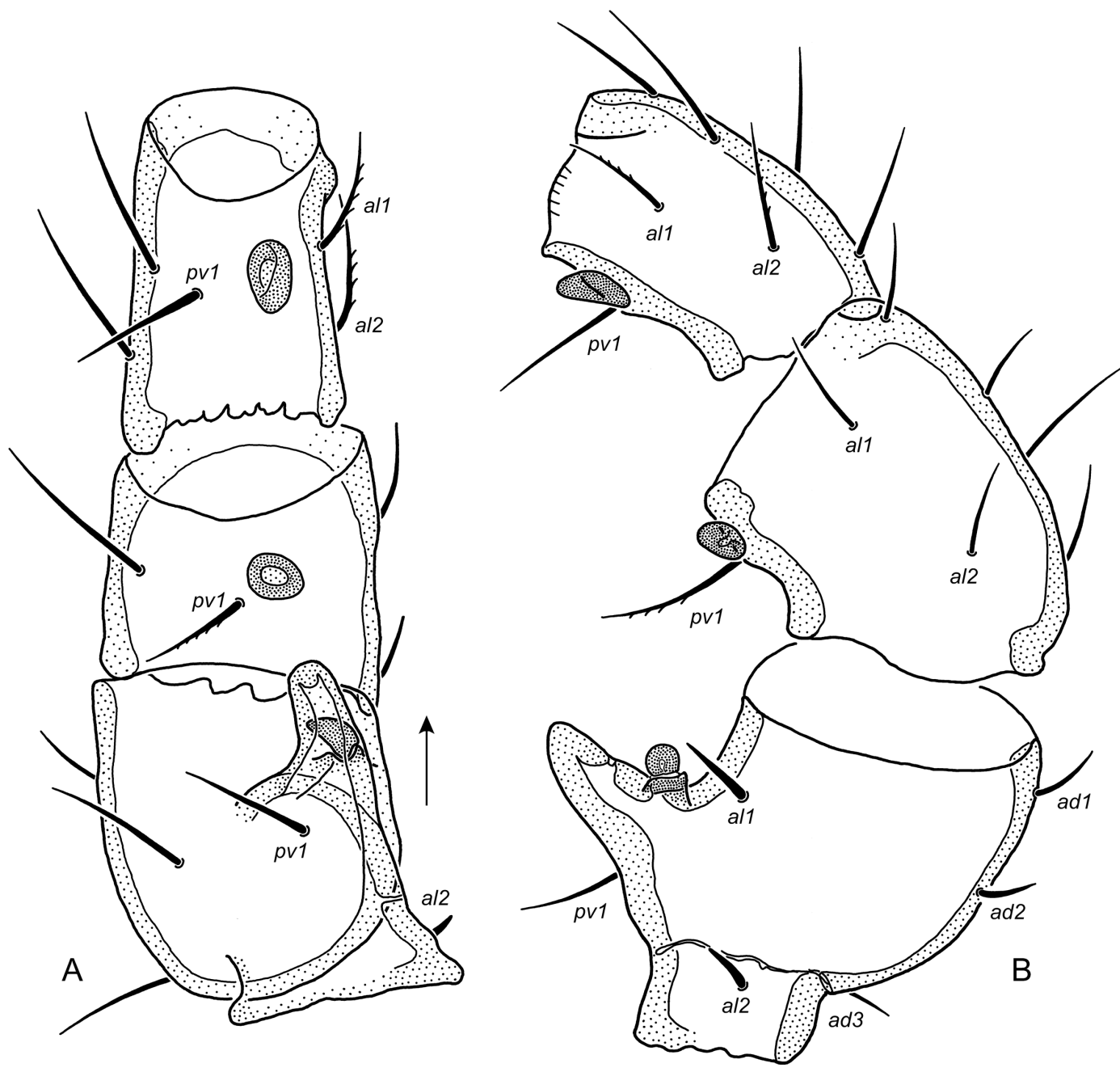

$\underline{A, B}$

$0.1 \mathrm{~mm}$

Figure 5 Leptogamasus (L.) bucerus n. sp., male: A - Fe II, Ge II and Ti II, ventrally; B - Fe II, Ge II and Ti II in the anterolateral perspective. Some setae are marked, arrow at the anterolateral side.

2003, other data as in the holotype; 11 females, 7 males (slides no. 1819, 1922 C, 1930, 1931 A-C, 1937 C, 1955, 1963 A), litter and moss on the rocks, other data as in the holotype, leg. in part by M. Skorupski.

Type deposition. The types are deposited in the Zoological Division of the Nature Education Centre, Jagiellonian University, Kraków, Poland.

\section{Etymology}

The specific name bucerus (lat. (from gr.) bucerus = boasting large horns) refers to the large and forked stipule of the female endogynium.

\section{Leptogamasus (Leptogamasus) cortinis $\mathbf{n} . \mathbf{s p}$.}

(Figures 6-10) 


\section{Diagnosis}

Female and male. Gnathotectum trispinate with similar pointed prongs; gland pores $g v 1$ present; podonotum with 21 pairs of setae, opisthonotum with 24 pairs of setae plus one pair of supplementary setae located marginally; Tr IV without tubercle.

Female. Presternal plates moderately distant, with axially directed protrusions; sternal shield anterior margin arcuate; the anterior margins of epigynial shield slightly wavy, posterolateral ones short and convex, internal (dorsal) surface of the epigynium with two prominent teeth; endogynium with elongated spherules, their pointed anterior poles close together, endogynial sac walls with one pair of tubercles dorsally to the spherules; two lamellar teeth present below or in front of the spherular tips, stipule large and wide, usually directed ventrally, bearing several denticles in the central part.

Male. Genital lamina anterior and lateral margins concave, anterior corners rounded; presternal plates with circular central area; corniculi with tubercular protrusion on the ventral side; hypostome with arcuate thickenings at the corniculi level; chelicera movable digit with obliquely cut tip and one tooth, fixed digit narrow, bearing lamellar protrusion on the ventral margin in between pilus dentilis and digit apex, as well as a tubercular protrusion on the dorsal margin, followed be the margin incision; leg II from the lateral perspective with the femur main spur straight, finger-shaped, the axillary process half-moon shaped, spur on the genu rectangular, spur on the tibia conical, genual and tibial spurs in some distance from the distal article margins; posteroventral seta on the Ti IV thickened and barbed.

\section{Description}

Female (Figures 6-8)

Idiosoma. Moderately sclerotised, 580-600 x 285-305 (length x width, $\mathrm{n}=5$ ), holotype 592 x 306. Podonotum with 21 pairs of setae, setae length in paratypes: 23-25 (j1), 21-24 (j2), 34-39 (j3), 33-37 (j4), 29-31 (j5), 27-31 (j6), 78-85 (r3), in holotype $26(j 1), 25(j 2)$, $39(j 3), 38(j 4), 33(j 5), 27(j 6), 80(r 3)$. Opisthonotum (Fig. 6) with 24 pairs of setae and one supplementary pair located marginally. Setae length from ca. 18 (some marginal) to 30 (J6). Dorsal setae simple, reticulation of podonotum absent, opisthonotum with a scale-like reticulation. Peritreme (Fig. 7A) - length in paratypes 144-152, including stigma, in holotype 146 , ending anteriorly in front of the podonotal setae $r 2$.

Ventral idiosoma (Fig. 7A). Setae length in paratypes: 37-41 (st1), 39-46 (st2), 37-42 (st3), 37-41 (st4), 37-39 (st5), 35-38 (JV1), 22-25 (ZV1), other opisthogastric setae ca. 26-37. In holotype 35 (st1), 38 (st2), 38 (st3), 39 (st4), 38 (st5), 37 (JV1), 24 (ZV1). Ventral setae simple, reticulation of the opisthogaster scale-like. Anterior margin of the sternal shield arcuate, presternal plates moderately distant at the thickness of tritosternum, each one with an adaxial protrusion, the area between the presternal plates and the sternum margin with reticulation. The pores gvl located axially, not far one another, and close to the posterior margin of the sternum. Paragynial shields (Figs 7A, 8A) with arcuate metagynial sclerites. Epigynial shield (Figs 7A, 8B), the anterior margins slightly wavy, posterolateral ones convex, and the posterior margin straight. A less pigmented area is located subapically. Two prominent teeth present on the internal (dorsal) surface of the epigynium. Endogynium (Figs 7A, 8C-E) with elongated spherules, their anterior poles pointed and convergent, dorsally to the spherules the endogynial sac walls bear one pair of axially directed tubercles (Fig. 8C,D), two lamellar teeth are present below or in front of the spherular tips (Fig. 8D). Stipule (Fig. 8C, E) is large and wide, usually directed ventrally, with several denticles in its central part. Gland pores gv2 with one opening; iv5, ivo2, ivo3, and gv3 clearly visible.

Gnathosoma. Gnathotectum (Fig. 8F) trispinate, all prongs similar, narrow and acute, the central one somewhat longer. Corniculi conical, hypostome with 10 rows of denticles, hypostomal and palpcoxal setae simple. Palptrochanter seta $v 1$ simple, $v 2$ larger and barbed. Chelicera (Fig. 8G) - movable digit with four teeth, the proximalmost larger. Fixed digit with two teeth in front and two behind pilus dentilis, followed by a low lamellar protrusion. 


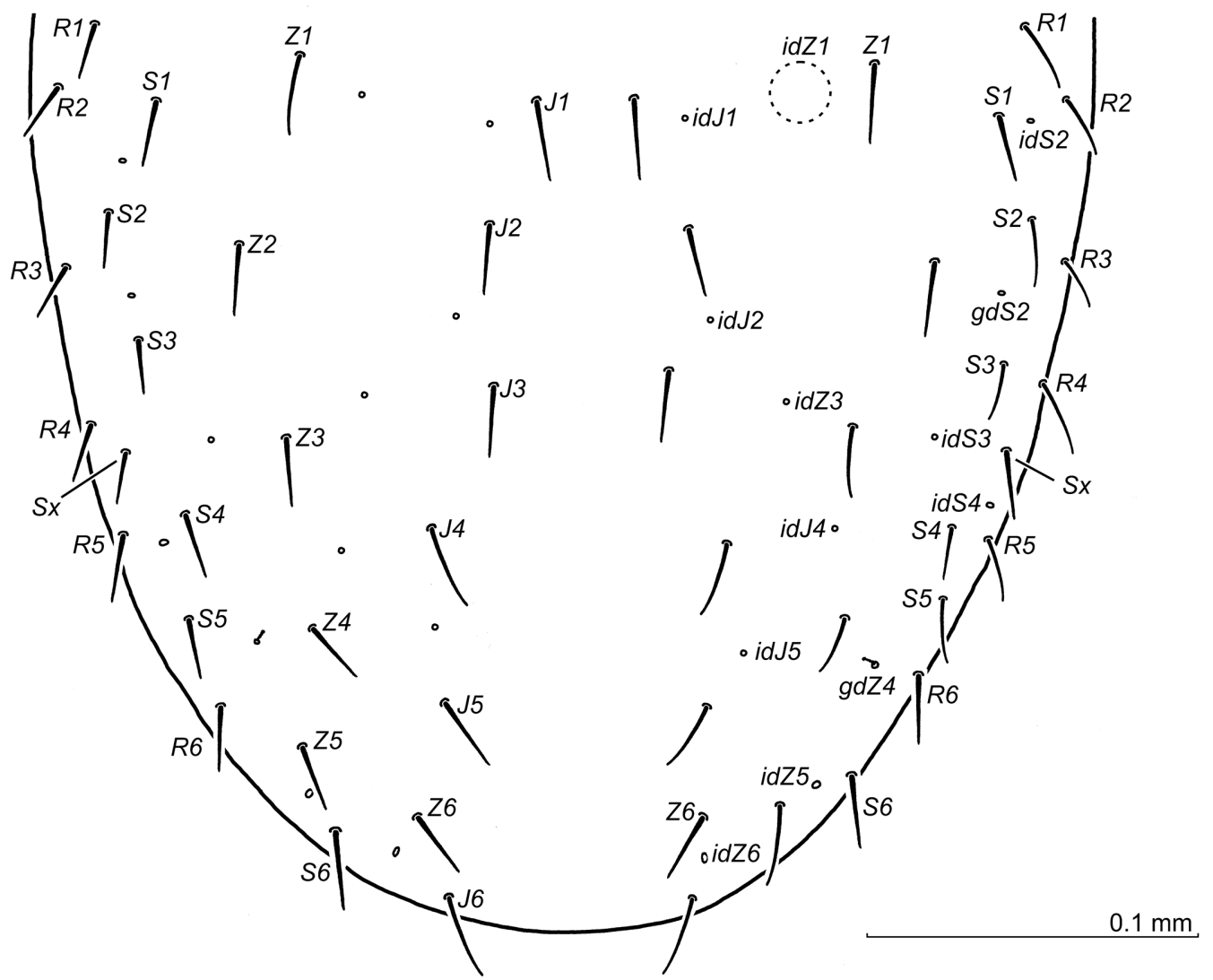

Figure 6 Leptogamasus (L.) cortinis $\mathbf{n}$. sp., opisthonotum of the female (holotype).

Legs. Setae $a l$ on $\operatorname{Tr}$ I and $a d 2$ on Fe I short and somewhat thickened. Fe II anteroventral seta larger and barbed, setae all and al2 short and thick. Seta all on Ge II, anteroventral seta and both anterolateral setae on Ti II barbed. Leg IV: posterodorsal and posterolateral setae on the femur shorter and thicker, posteroventral seta on the genu finely barbed, posteroventral seta on the tibia enlarged and barbed (Fig. 7B). Some setae on the tarsi barbed. Tr IV without tooth/ tubercle. Other aspects of legs I-IV unremarkable.

Male (Figures 9, 10)

Idiosoma. Sclerotised and reticulated as in the female, 530-565 x 260-280 (length x width, $\mathrm{n}=5$ ), body incised laterally at level of legs IV. Podonotum setae length: 33-38 (j1), 31-37 (j2), 31-39 (j3), 30-35 (j4), 26-31 (j5), 22-25 (j6), 77-81 (r3). Opisthonotum setae length from ca. 20 to 30 . Dorsal setae simple. Peritreme length 139-144, including stigma, ending anteriorly just in front of the podonotal setae $r 2$.

Ventral idiosoma. Setae length: 25-29 (st1), 27-31 (st2), 25-27 (st3), 22-27 (st4), 22-26 (st5), 27-31 (JV1), 20-23 (ZV1), other opisthogastric setae ca. 17-27. Ventral setae simple. Sternal region (Fig. 9A) - anterior margin of genital lamina concave, lateral margins slightly concave, the anterior corners rounded (Fig. 9A,B). Presternal plates with circular central area, rounded, with sharp anterior protrusions (Fig. 9A). Gland pores gvl close to the st 3 setae level, followed by two pairs of thickenings of the sternal cuticle. The anterior thickenings are quite indistinct and axially elongated, the posterior ones well developed, rounded and small, distributed more laterally. Pores gv2 with one opening, pore $i v 5$ halfway between st 5 and $Z V 1$ setae, ivo2, ivo3, and gv3 well developed. 


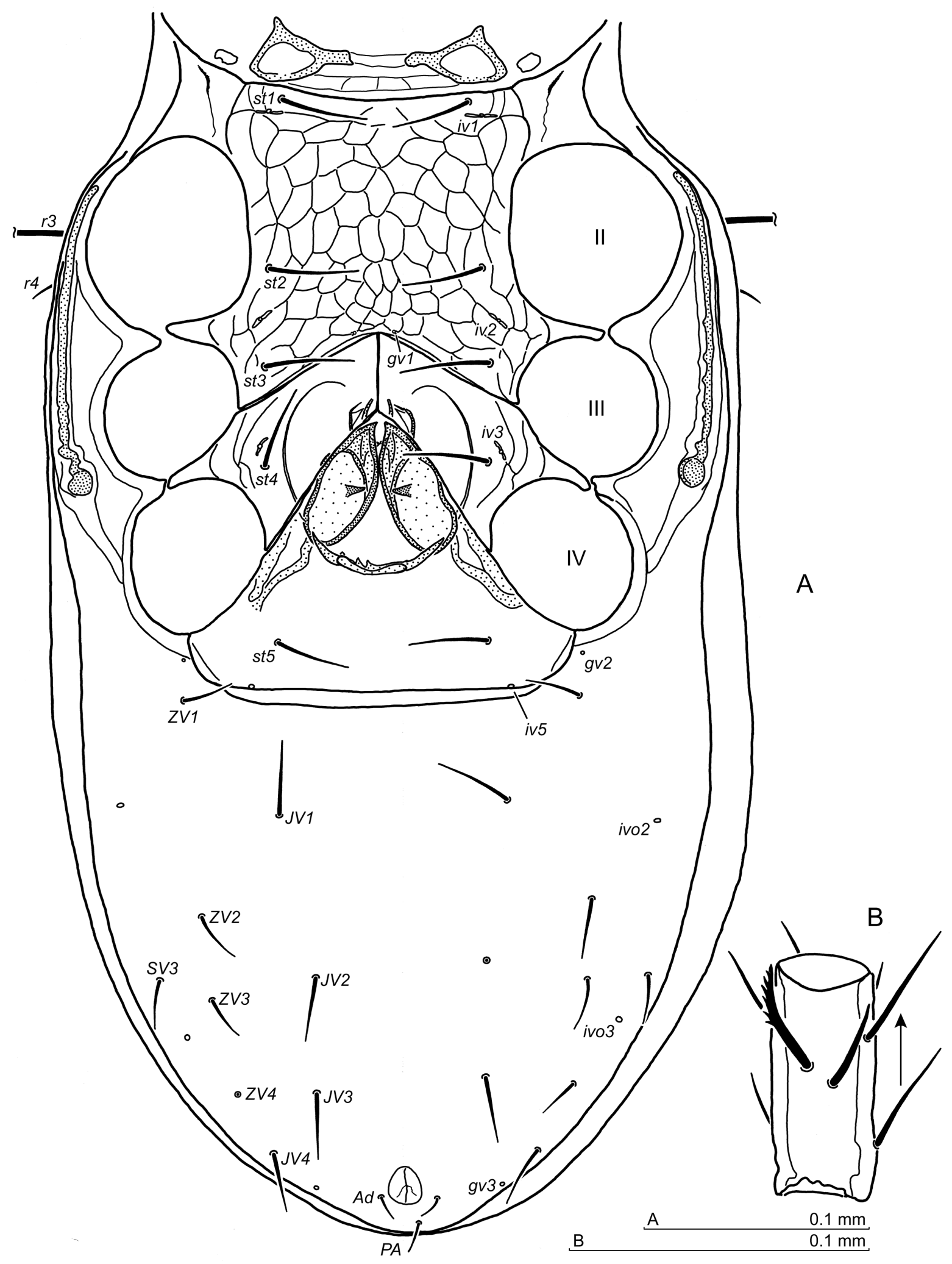

Figure 7 Leptogamasus (L.) cortinis $\mathbf{n}$. sp., female: A - ventral side of idiosoma, holotype. B - Ti IV ventrally, arrow at the anterolateral side. Abbreviations as in Figure 2, r3, r4 - podonotal setae. 

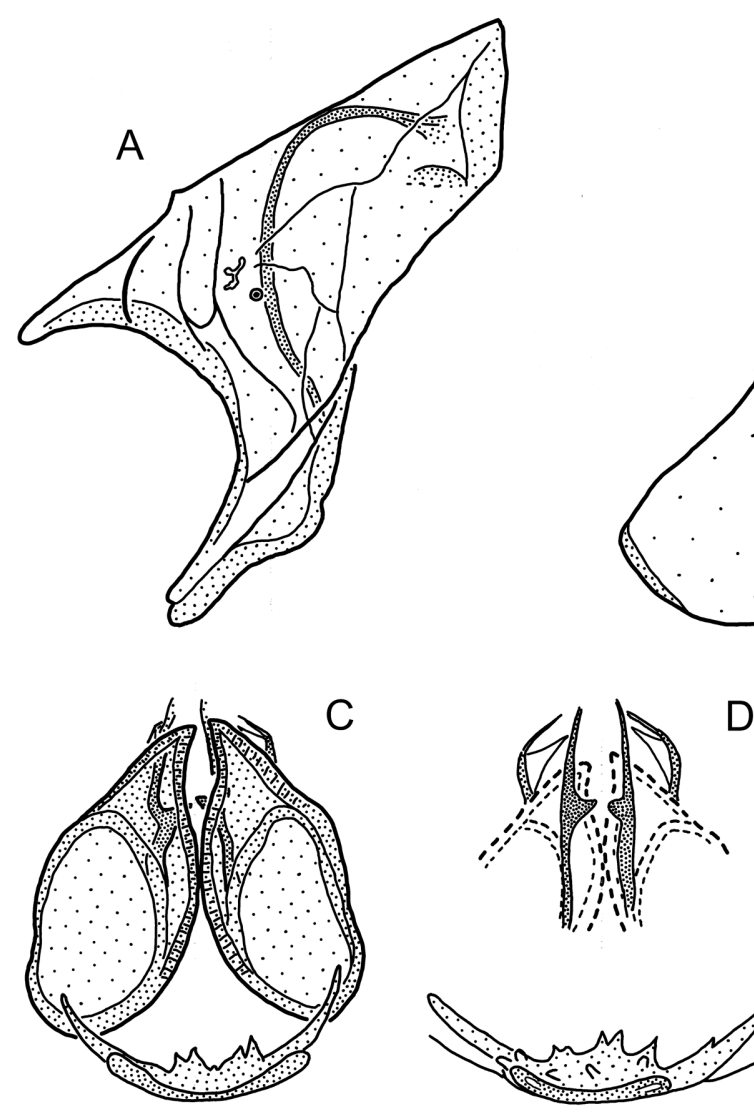

D
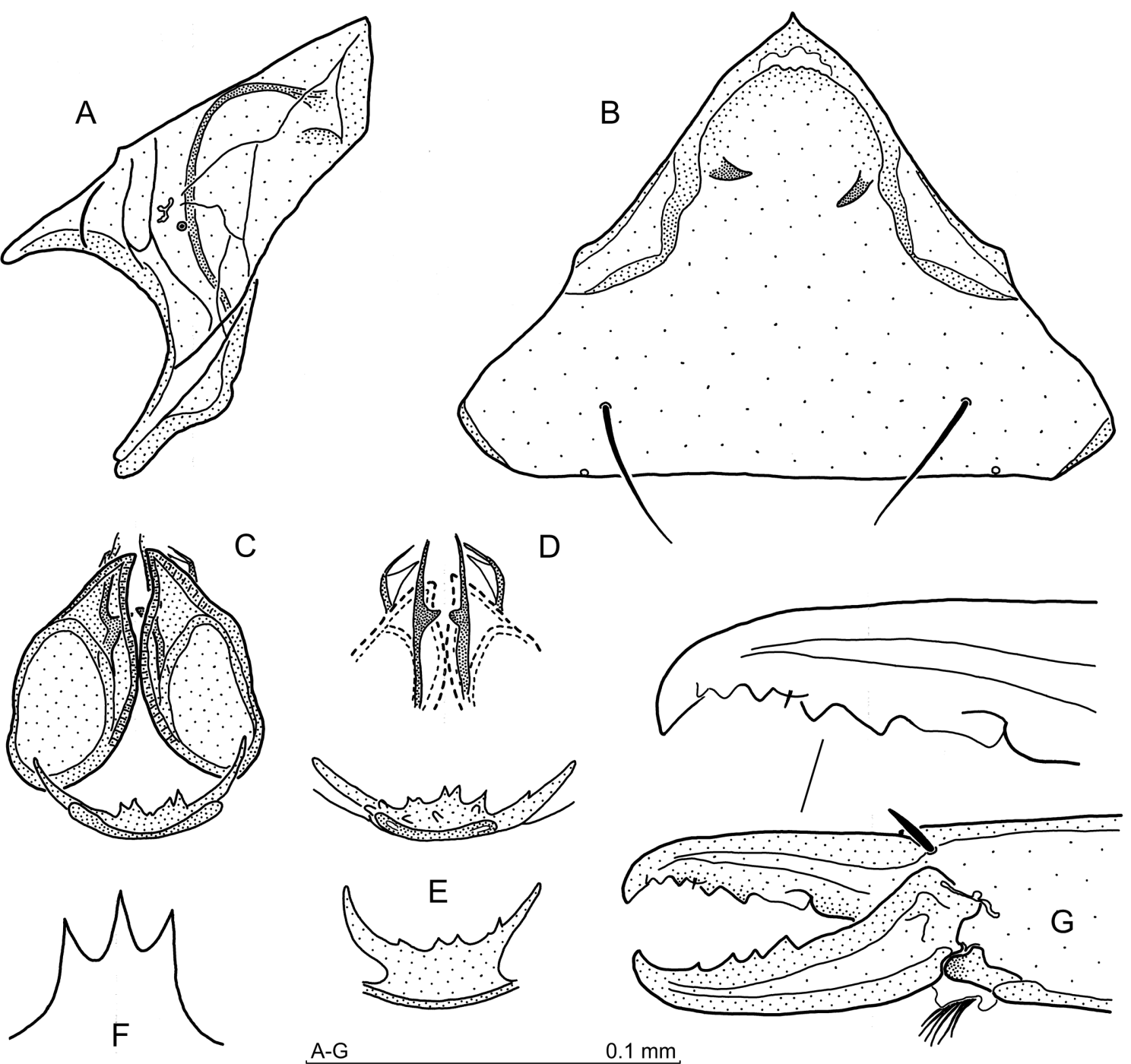

Figure 8 Leptogamasus (L.) cortinis n. sp., female: A - paragynium; B - epigynium; C - endogynium, ventrally; D - endogynium anterior part, dorsal aspect; E - stipule, two aspects; F - gnathotectum; G - chelicera, antiaxially. D - holotype. 

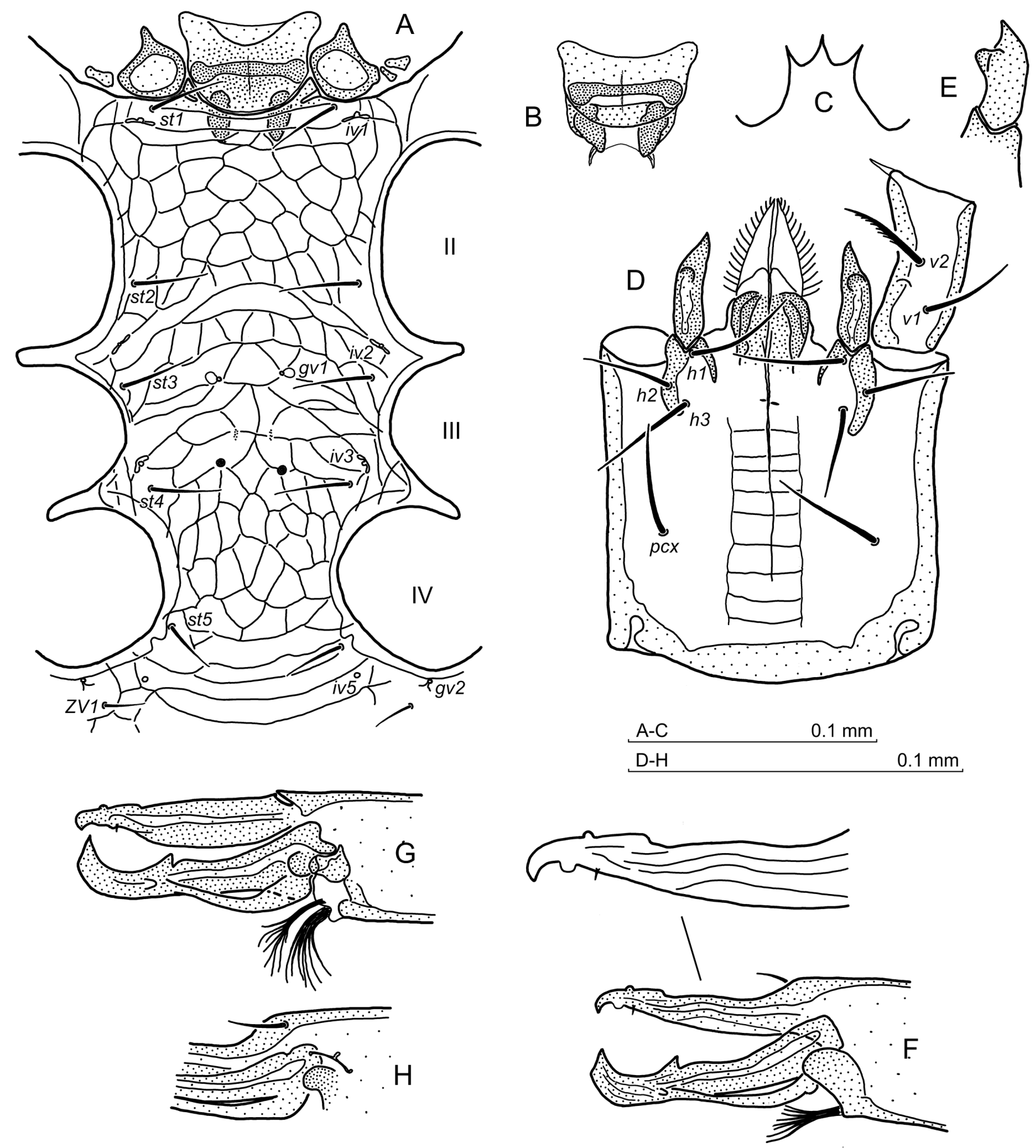

Figure 9 Leptogamasus (L.) cortinis n. sp., male: A - presternal plates, genital lamina and sternogenital shield; B - genital lamina; C gnathotectum; D - gnathosoma, ventrally, note the thickenings at the base of the internal malae; E - corniculus, laterally; $\mathrm{F}-$ chelicera, adaxially; $\mathrm{G}$ - chelicera, antiaxially; $\mathrm{H}$ - basal part of the cheliceral fixed digit, antiaxially. Abbreviations as in Figure 4. 


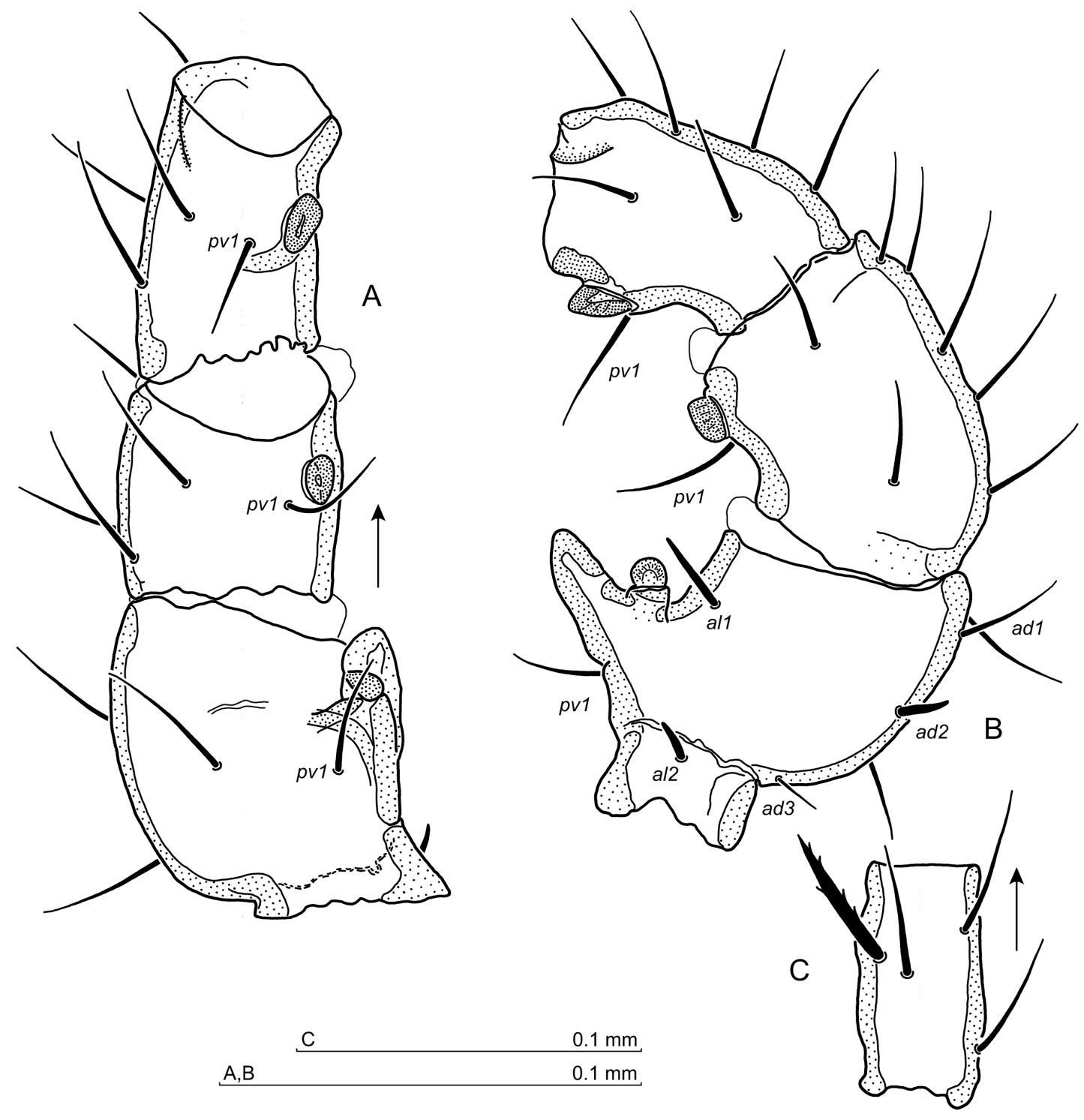

Figure 10 Leptogamasus (L.) cortinis n. sp., male: A - Fe II, Ge II and Ti II, ventrally; B - Fe II, Ge II and Ti II in the anterolateral perspective. Some setae are marked. C - Ti IV ventrally. Arrows at the anterolateral side.

spur conical, both spurs located at some distance from the distal article margins. An arcuate elevation is present on the anterolateral side at the distal end of the tibia. Setae on leg II simple, femoral setae all thicker, $a l 2$ and $a d 2$ thicker and shorter, $a d 3$ needle-shaped. Leg IV: trochanter without tooth/tubercle, posterodorsal and posterolateral setae on the femur shorter and thicker, posteroventral seta on the tibia thickened and barbed (Fig. 10C). Other aspects of legs I-IV unremarkable.

\section{Material examined}

Holotype. Female (slide no. 1670), Cortina d'Ampezzo, Dolomites, Italy, $46.5722^{\circ} \mathrm{N}$, $12.1132^{\circ} \mathrm{E}$, alt. ca. $1312 \mathrm{~m}$ a.s.l., 10 Sept. 2002, spruce forest litter. Paratypes. 13 females, 7 males (slide no. 1370 ), Cortina d'Ampezzo, Dolomites, Italy, $46.5159^{\circ} \mathrm{N}, 12.1350^{\circ} \mathrm{E}$, alt. ca. 
$1120 \mathrm{~m}$ a.s.1., 7 Sept. 2000, wet moss and litter in a mixed forest; 22 females, 5 males (slides no. 1872 A-F, 1874, 1875), Cortina d'Ampezzo, Dolomites, Italy, $46.5696^{\circ} \mathrm{N}, 12.1149^{\circ} \mathrm{E}$, alt. ca. $1303 \mathrm{~m}$ a.s.1., 11 Sept. 2004, moss on soil and tree stumps in a spruce forest; 1 female (slide no. 2009), Val Travenanzes, Cortina d'Ampezzo, Dolomites, Italy, $46.5945^{\circ} \mathrm{N}, 12.1130^{\circ} \mathrm{E}$, alt. ca. 1347 m a.s.1., 12 Sept. 2005, grass and litter in a spruce forest. Other material. 7 females, 5 males (slides no. 1212, 1214, 1215, 1218, 1220, 1221), Cortina d'Ampezzo, Dolomites, Italy, $46.5159^{\circ} \mathrm{N}, 12.1350^{\circ} \mathrm{E}$, alt. ca. $1120 \mathrm{~m}$ a.s.l., 6 Sept. 1999 , wet moss and litter in a mixed forest; 21 females, 21 males (slides no. 1369, 1372, 1373, 1619), 7 Sept. 2000, remaining data ibid.; 1 female, 2 males (slide no. 1776), track to Col Rosa Mt., Cortina d'Ampezzo, Dolomites, Italy, $46.5797^{\circ} \mathrm{N}, 12.0973^{\circ} \mathrm{E}$, alt. ca. $1680 \mathrm{~m}$ a.s.1., 2 Sept. 2003 , litter under beech in a spruce forest; 8 females, 5 males (slide no. 2019), Cortina d'Ampezzo, Dolomites, Italy, $46.5723^{\circ} \mathrm{N}$, $12.1124^{\circ} \mathrm{E}$, alt. ca. $1325 \mathrm{~m}$ a.s.1., 13 Sept. 2005 , moss on soil and tree stumps in a spruce forest.

Type deposition. Types are deposited in the Zoological Division of the Nature Education Centre, Jagiellonian University, Kraków, Poland, all remaining material is held in the author's collection.

\section{Etymology}

The specific name cortinis refers to immediate surroundings of Cortina d'Ampezzo, where all the types were collected.

Leptogamasus (Leptogamasus) silvestris $\mathbf{n} . \mathbf{s p}$.

Zoobank: 37C79551-31D8-4F40-B5BF-5A7B723AF3BF

(Figures 11-15, 19C)

\section{Diagnosis}

Female and male. Gnathotectum trispinate with similar, triangular and pointed prongs; gland pore $g v 1$ present; podonotum with 21 pairs of setae, opisthonotum with 24 pairs of setae plus one pair of supplementary setae located marginally; Tr IV without tubercle.

Female. Presternal plates distance similar to the thickness of tritosternum; sternal shield anterior margin with shallow concavity; the anterior margins of the epigynial shield straight, posterolateral ones short and convex, the apical part of the epigynium less pigmented; the internal (dorsal) surface of the epigynium without teeth; endogynial spherules roundish posteriorly and tapered anteriorly, with anterior parts convergent and bearing 3-4 teeth each; stipule short, richly dentate, located between the spherular posterior parts.

Male. Genital lamina with the anterior corners rounded; presternal plates subrectangular, with anterior protrusions and a rounded posterior margin; corniculi with adaxial elevation and slightly thickened antiaxial margins; cheliceral fixed digit straight and narrow, its apex cut obliquely, an arcuate lamellar protrusion present between the apex and the pilus dentilis, posteriorly to the pilus dentilis the edge of the digit forms a low, acute culmination; leg II femoral main spur straight, the axillary process half-moon to finger-shaped; genual and tibial spurs at some distance from the article distal margin, the genual spur tuberculate, the tibial spur conical, larger and pointed.

\section{Description}

Female (Figures 11-13, 19C)

Idiosoma. Moderately sclerotised, 600-635 x 360-375 (length x width, $\mathrm{n}=5$ ), holotype $590 \times 361$. Podonotum with 21 pairs of setae, setae length in paratypes: $33-37(j 1), 38-41$ (j2), 38-42 (j3), 35-37 (j4), 26-29 (j5), 24-26 (j6), 63-72 (r3), in holotype 34 (j1), $37(j 2)$, 39 (j3), 33 (j4), 26 (j5), 22 (j6), 67 (r3). Opisthonotum (Fig. 11) with 24 pairs of setae and one supplementary pair located marginally. Setae length from ca. 21 (some marginal) to 33 (J6). Dorsal setae simple, podonotum with poorly discernible reticulation between setae $\mathrm{j} 3$ and j4 levels, opisthonotum with a scale-like reticulation. Peritreme length 137-150, including 


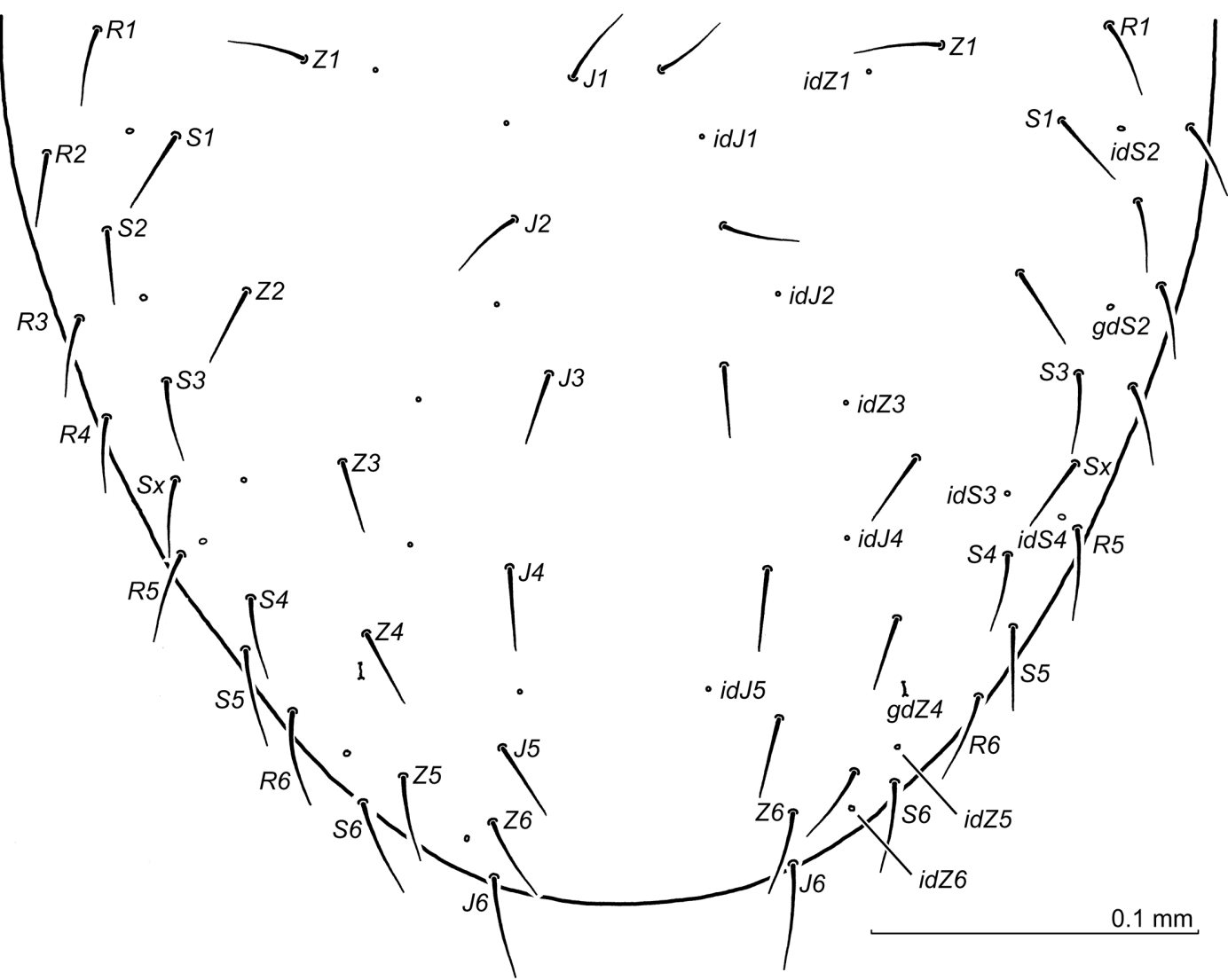

Figure 11 Leptogamasus (L.) silvestris n. sp., opisthonotum of the female.

stigma (holotype 149), ending anteriorly in the midregion of the opening for Co II, at the level of the podonotal setae $r 2$.

Ventral idiosoma (Fig. 12) Setae length: 37-42 (st1), 38-43 (st2), 39-45 (st3), 34-42 (st4), 32-41 (st5), 34-38 (JV1), 26-30 (ZV1), other opisthogastric setae ca. 33-47, in holotype 33 (st1), 38 (st2), 39 (st3), 31 (st4), 31 (st5), 34 (JV1), 25 (ZV1). Ventral setae simple, reticulation of the opisthogaster scale-like. Anterior margin of the sternal shield (Figs 12A, 19C) with shallow concavity, the area between the presternal plates and the sternum margin with transverse lines. Presternal plates form the adaxial protrusions distant similarly to the thickness of tritosternum. The pores $g v 1$ located axially not far from one another, and close to the posterior margin of the sternum. Paragynial shields (Figs 12A, 13A) with narrow and anteriorly arcuate metagynial sclerites. Epigynial shield (Figs 12A, 13B), with apical part less pigmented, the anterior margins straight, posterolateral ones short and convex. The internal (dorsal) surface of the epigynium devoid of any teeth. Spherules of the endogynium (Figs 12A, $13 \mathrm{C}$ ) roundish posteriorly and tapered anteriorly. The anterior parts convergent and bearing 3-4 teeth each. Stipule is located between the spherular posterior parts and bears numerous, rather short teeth, both anteriad and posteriad, as well as ventrally directed. Gland pores gv2 with two openings, iv5, ivo2, ivo3, and gv3 clearly visible.

Gnathosoma. Gnathotectum (Fig. 13D) trispinate, all prongs narrow and acute, similar in shape, the central one slightly longer. Corniculi conical, hypostome with 10-11 rows of 


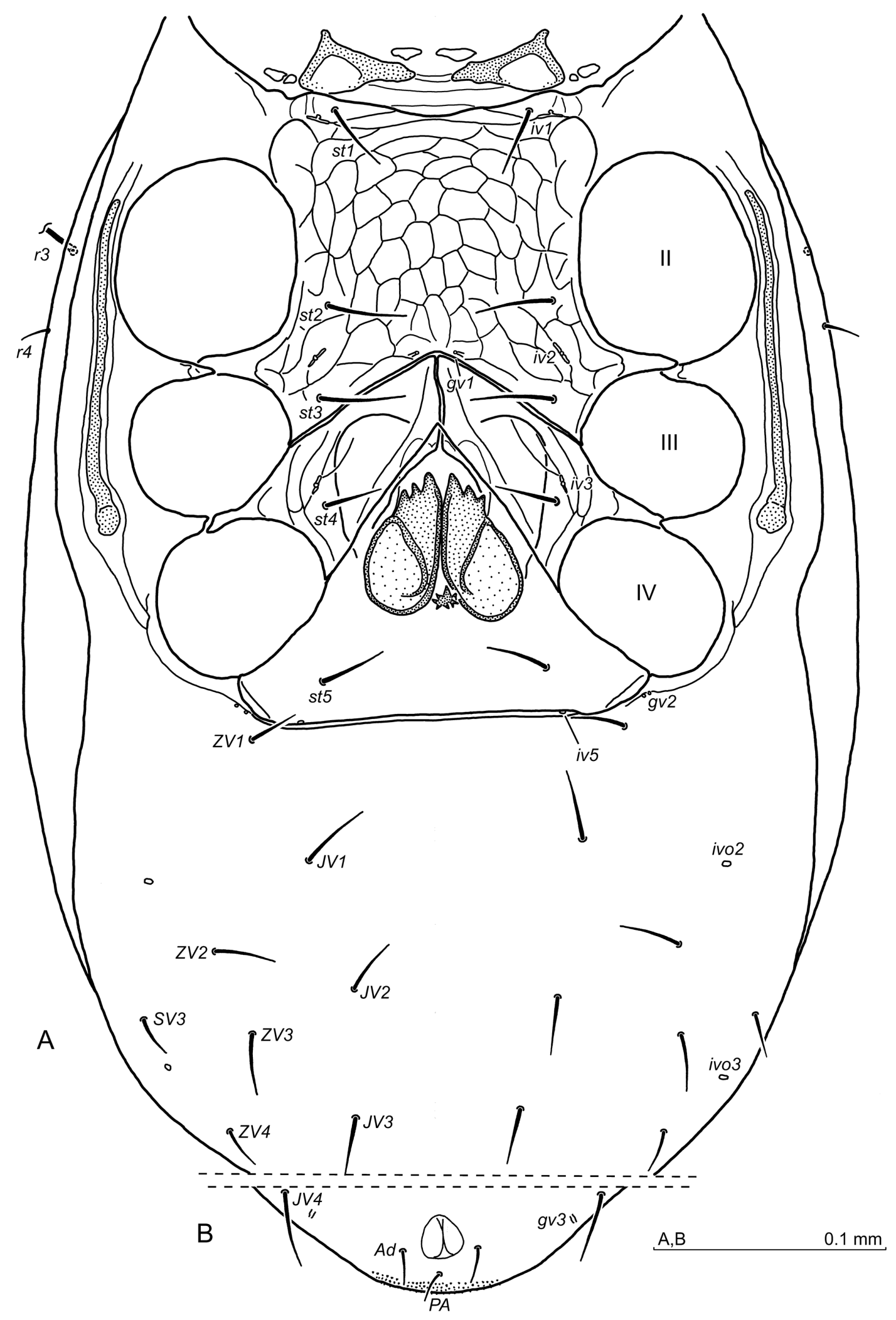

Figure 12 Leptogamasus (L.) silvestris n. sp., female: A - ventral side of idiosoma, holotype. B -perianal region of idiosoma in other specimen. Abbreviations as in Figure 7. 


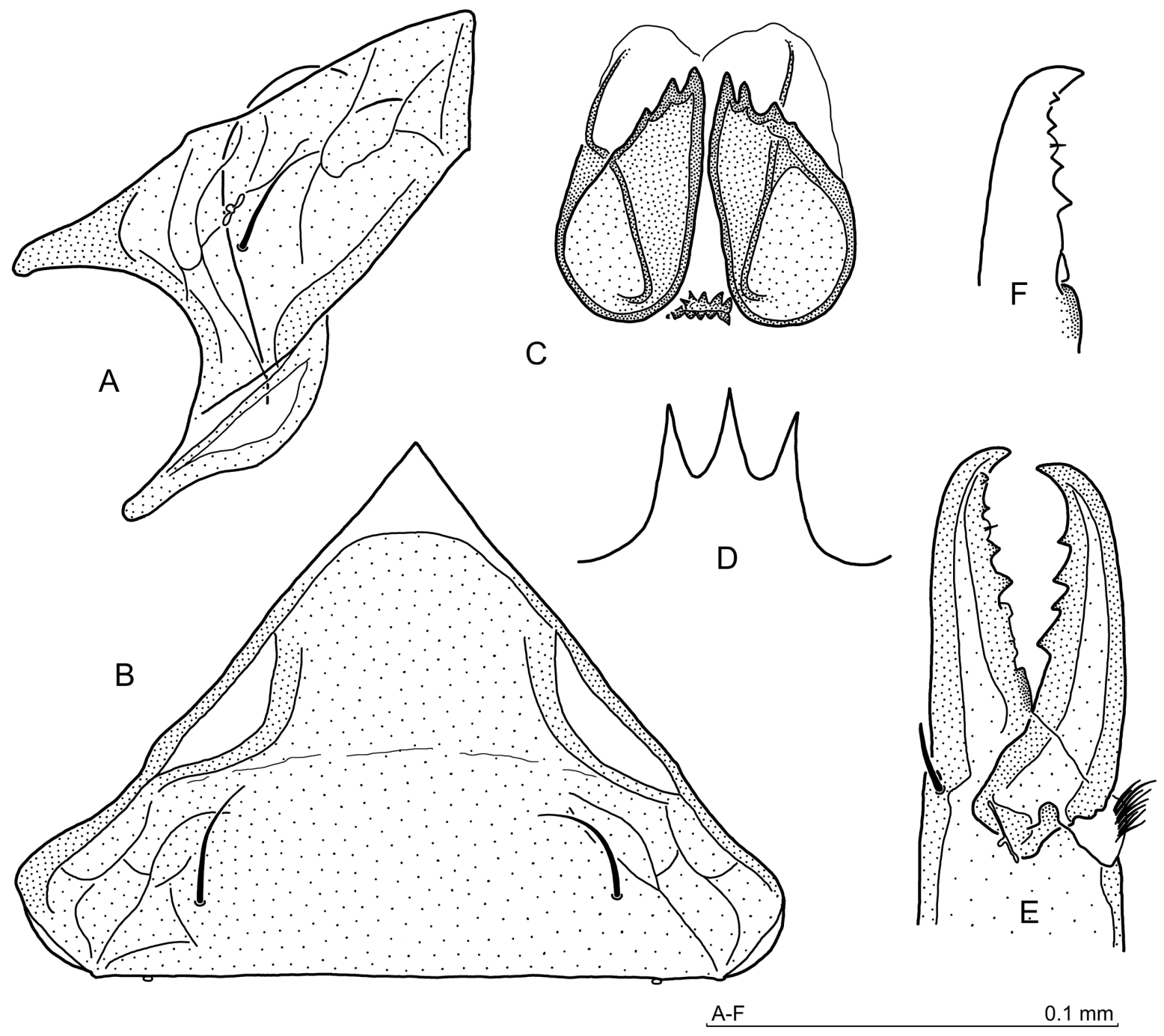

Figure 13 Leptogamasus (L.) silvestris n. sp., female: A - paragynium; B - epigynium; C - endogynium; D - gnathotectum; E - chelicera, antiaxially; F - cheliceral fixed digit, other antiaxial aspect.

denticles, hypostomal and palpcoxal setae simple. Palptrochanter seta $v 1$ simple, $v 2$ barbed. Chelicera (Fig. 13E,F) - movable digit with four teeth, the proximal one larger, fixed digit with 2 distant teeth in front of the pilus dentilis, arcuate tooth by the side of the pilus dentilis, and two teeth behind the pilus dentilis, followed by a lamellar edge.

Legs. Setae $a l$ on $\operatorname{Tr}$ I somewhat shorter and thicker. Leg II: anterolateral seta on $\operatorname{Tr}$ II and anterolateral setae all, al 2 on Fe II shorter and thicker, anteroventral setae on Fe II, Ge II and Ti II larger and barbed. Leg IV: posterodorsal and posterolateral setae on the femur thick and short, posteroventral setae on the tibia, posterolateral setae on the basitarsus and the tarsus thickened and terminally barbed. Tr IV without tubercle. Other aspects of legs I-IV unremarkable.

Male (Figures 14, 15)

Idiosoma. Moderately sclerotised, 545-565 x 285-315 (length $\mathrm{x}$ width, $\mathrm{n}=5$ ), body oval. Podonotum setae length: 30-35 (j1), 27-33 (j2), 30-33 (j3), 26-31 (j4), 22-25 (j5), 18-21 (j6), 58-63 ( $r 3$ ). Opisthonotum setae length from ca. 18 to 26. Dorsal setae simple. Reticulation of 

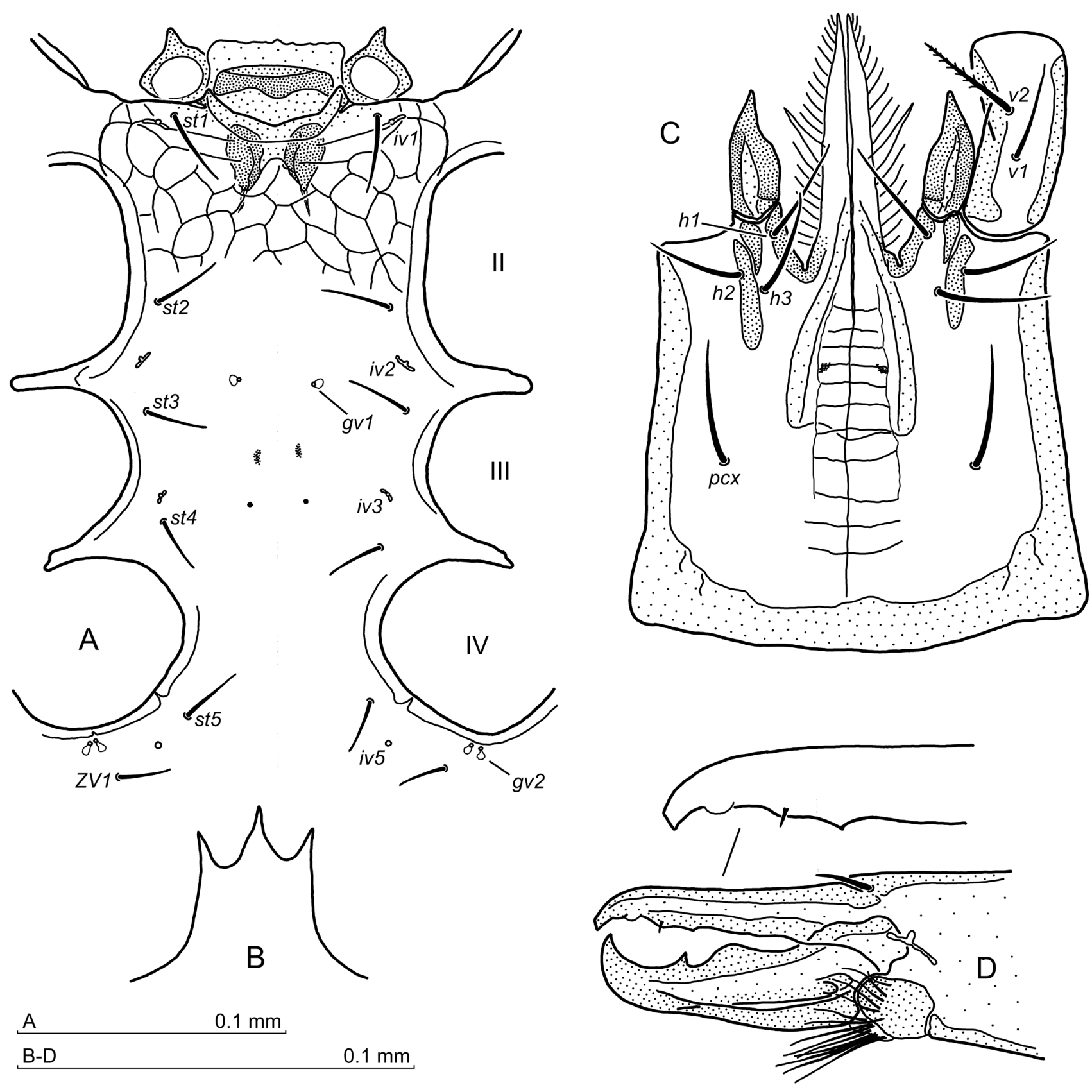

Figure 14 Leptogamasus $($ L. ) silvestris n. sp., male: A - presternal plates, genital lamina and sternogenital shield; B - gnathotectum; C gnathosoma, ventrally; D - chelicera, antiaxially. Abbreviations as in Figure 4. 


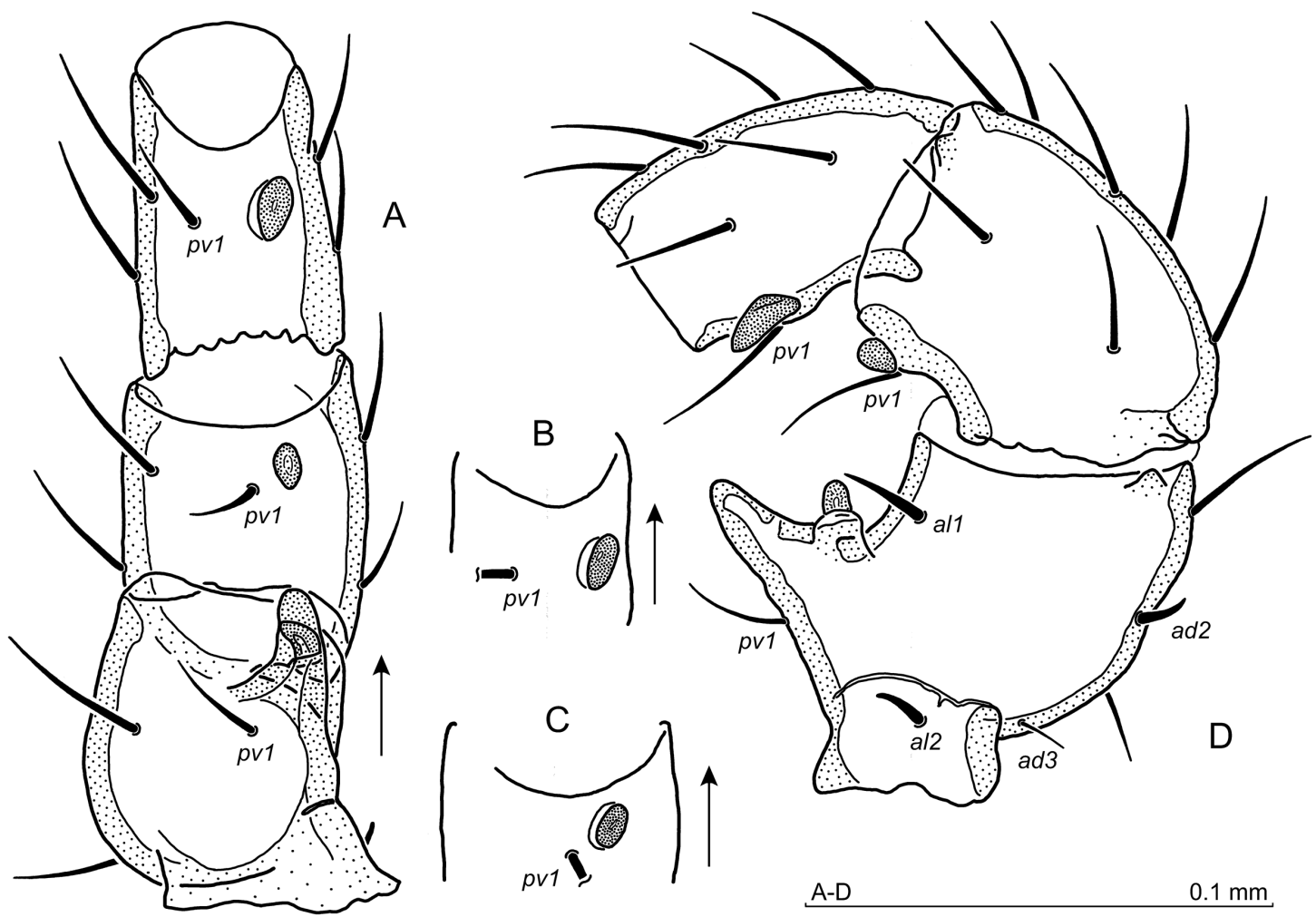

Figure 15 Leptogamasus (L.) silvestris n. sp., male: A - Fe II, Ge II and Ti II, ventrally; B - Ti II spur location; C - Ge II spur location; D Fe II, Ge II and Ti II in the anterolateral perspective. Some setae are marked. Arrows at the anterolateral side.

the podonotum non-discernible, opisthonotum with a scale-like reticulation. Peritreme length including stigma 133-142, ending anteriorly as in the females.

Ventral idiosoma. Setae length: 25-29 (st1), 29-34 (st2), 26-31 (st3), 22-26 (st4), 22-27 (st5), 27-31 (JVI), 19-22 (ZVI), other opisthogastric setae ca. 18-33. Ventral setae simple. Sternal region (Fig. 14A) - the anterior margin of genital lamina straight, with minute undulations, the anterior corners rounded. Presternal plates subrectangular, with a rounded posterior margin and clear central area. Sternum with gland pores $g v 1$ between $i v 2$ pores and $s t 3$ setae levels, followed by two pairs of thickenings of the sternal cuticle, the anterior ones elongated and the posterior ones minute and button-shaped. Pores $g v 2$ with two distinct openings, pores $i v 5$ halfway between $s t 5$ and $Z V 1$ setae, $i v o 2$, $i v o 3$, and $g v 3$ clearly visible.

Gnathosoma. Gnathotectum (Fig. 14B) trispinate, central prong longer and wider basally. Corniculi (Fig. 14C) with an elevation on the adaxial surface and the thickened antiaxial margins, hypostome with 11 rows of denticles, hypostomal and palpcoxal setae simple. Palptrochanter seta $v 1$ simple, $v 2$ barbed (Fig. 14C). Chelicera (Fig. 14D). When observed from the ventral side, mobile digits curved adaxially and shorter than the straight fixed ones. Laterally (Fig. 14D), mobile digit with one tooth followed by an arcuate edge proximally; fixed digit straight and narrow with obliquely cut apex, bearing a low and arcuate lamellar protrusion between the apex and the pilus dentilis, and a low acute culmination behind the pilus dentilis.

Legs. Leg II (Fig. 15A-D) spurred as follows: when viewed from the ventral side (Fig. $15 \mathrm{~A}-\mathrm{C}$ ), the femoral main spur slightly curved, the axillary process curved posterolaterally, genual spur smaller than the tibial one and variably directed (Fig. 15A,C). From a lateral perspective (Fig. 15D), the femoral main spur straight, the axillary process half-moon to 
finger shaped. The spur on the genu tubercular and low, tibial spur conical and pointed, both spurs located at some distance from the distal article margins. Setae on leg II simple, femoral seta all thicker, al2 and $a d 2$ thicker and shorter, ad3 needle-shaped. Leg IV: trochanter without tooth/tubercle, posterodorsal and posterolateral setae on the femur shorter and thicker, posteroventral seta on the tibia thickened and barbed terminally. Other aspects of legs I-IV unremarkable.

\section{Material examined}

Holotype. Female (slide no. 1922 A), Cansiglio Forest, Cansiglio, northern Italy, 46.0484 ${ }^{\circ} \mathrm{N}, 12.3985^{\circ} \mathrm{E}$, alt. ca. $1065 \mathrm{~m}$ a.s.l., 29 July 2003, beech forest litter, leg. M. Skorupski. Paratypes. 1 male (slide no. 1922 B), ibid., 4 females, 3 males (slides no. 981 A-G), Cansiglio Forest, Cansiglio, northern Italy, 13 Oct. 1984, beech forest litter, collected by the staff of the Dept. of Evolutionary Biology, University of Siena, Italy. Other material. 3 females, 3 males (slide no. 1924), data as in holotype; 5 females, 7 males (slide no. 1767 C), Cansiglio Forest, Cansiglio, northern Italy, $46.0473^{\circ} \mathrm{N}, 12.3977^{\circ} \mathrm{E}$, alt. ca. $1118 \mathrm{~m}$ a.s.1., 29 July 2003, moss on soil and rocks, leg. M. Skorupski; 5 females, 4 males (slides no. 1937 A,B, 1939, 1962, 1963 B), Cansiglio Forest, Cansiglio, northern Italy, $46.0482^{\circ} \mathrm{N}, 12.3971^{\circ} \mathrm{E}$, alt. ca. $1090 \mathrm{~m}$ a.s.l., 29 July 2003, beech forest litter, leg. M. Skorupski; 2 females (slide no. 1745), Tiriton, near Campon, Veneto, northern Italy, $46.1036^{\circ} \mathrm{N}, 12.4114^{\circ} \mathrm{E}$, alt. ca. $1050 \mathrm{~m}$ a.s.1., 30 July 2003, litter under beech tree in spruce forest; 2 females, 2 males (slide no. 1746), moss in spruce forest, remaining data ibid.; 1 female (slide no. 1843), Tambre, via Castiglio, northern Italy, $46.1229^{\circ} \mathrm{N}, 12.3729^{\circ} \mathrm{E}$, alt. ca. $685 \mathrm{~m}$ a.s.1., 30 July 2003 , deciduous forest litter.

Type deposition. Types are deposited in the Zoological Division of the Nature Education Centre, Jagiellonian University, Kraków, Poland, all remaining material is held in the author's collection.

\section{Etymology}

The specific name silvestris (lat., living in the forest) refers to a large forest (Bosco di Cansiglio) where all the types were collected.

\section{Leptogamasus (Leptogamasus) parasilvestris n. sp.}

Zoobank: 4D07B2E7-9C9E-47AB-8550-AAC0087560A5

(Figures 16-21)

\section{Diagnosis}

Female and male. Gnathotectum trispinate with similar, triangular and pointed prongs, in females the central one longer; gland pore gvl present; podonotum with 21 pairs of setae, opisthonotum with 24 pairs of setae plus one pair or a single supplementary setae located marginally; Tr IV without tubercle.

Female. Presternal plates distance similar to the thickness of the tritosternum; sternal shield anterior margin with shallow concavity; the anterior margins of epigynial shield straight, posterolateral ones short and convex, the apical part of the epigynium less pigmented; the internal (dorsal) surface of epigynium bears two small teeth close to the anterior margins; endogynial spherules roundish posteriorly and narrowed anteriorly, due to the concavity of lateral margins, with anterior parts bearing usually 2-3 teeth, but sometimes 1 or 4 ; stipule moderately long, richly dentate, located behind the spherular posterior parts.

Male. Genital lamina with the anterior corners rounded; presternal plates subrectangular with anterior protrusions and a narrow posterior margin; corniculi with the adaxial elevation and thickened antiaxial margins; hypostome with two bean-shaped thickenings at the base of internal malae; cheliceral fixed digit wavy and narrow, between the apex and the pilus dentilis a small tooth, followed by an arcuate lamellar protrusion, posteriorly to pilus dentilis the edge of the digit forms a low, acute culmination; leg II femoral main spur arcuate, the axillary process 


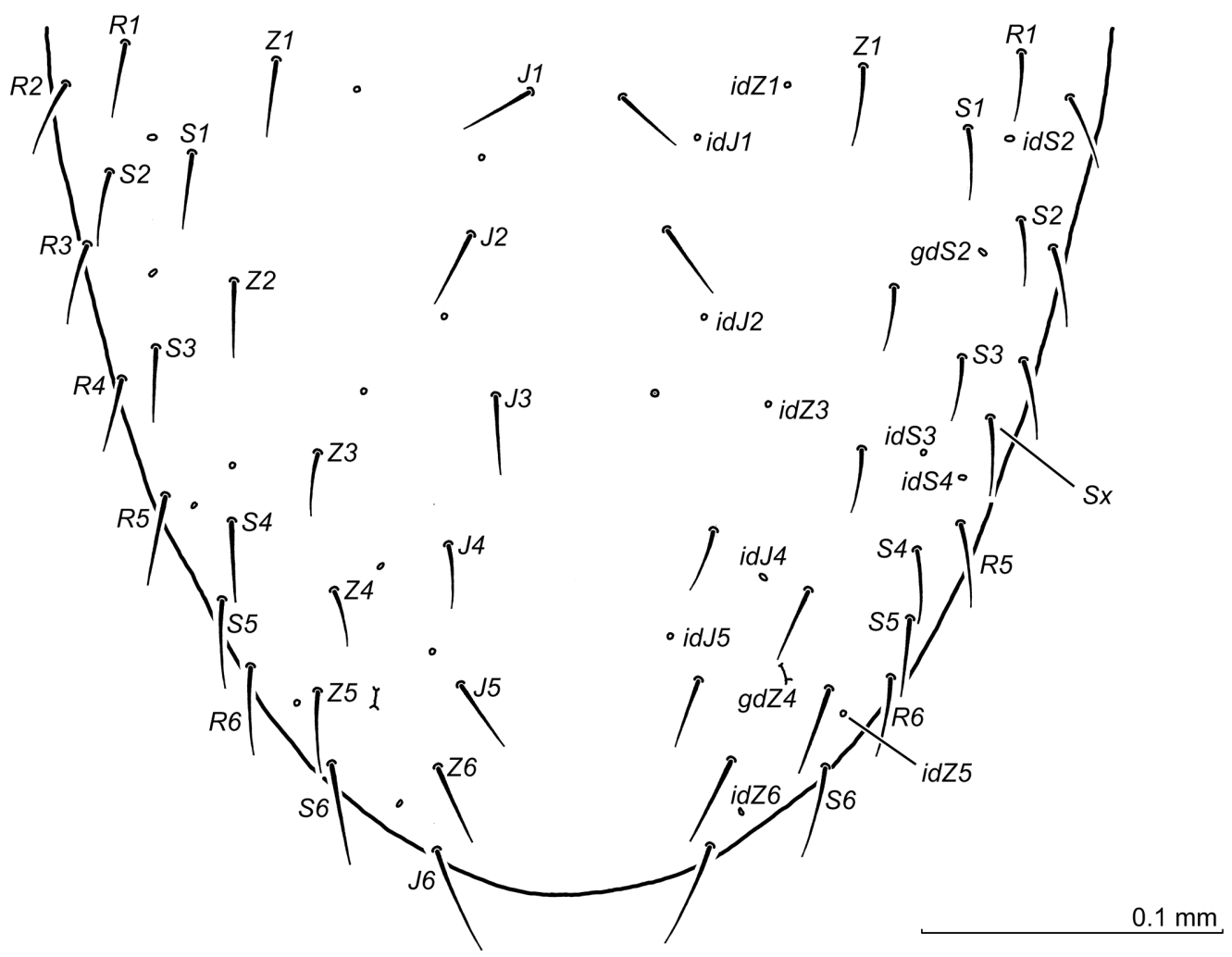

Figure 16 Leptogamasus (L.) parasilvestris $\mathbf{n} . \mathbf{s p}$., opisthonotum of the female.

half-moon shaped; genual and tibial spurs at some distance from the article distal margin, the genual spur roundish, the tibial one conical.

\section{Description}

Female (Figures 16-19)

Idiosoma. Moderately sclerotised, 600-620 x 320-340 (length x width, n=5), holotype $605 \times 335$. Podonotum with 21 pairs of setae, setae length in paratypes: 38-43 (j1), 31-39 (j2), 34-39 (j3), 31-35 (j4), 27-31 (j5), 25-29 (j6), 72-78 (r3), in holotype $38(j 1), 36(j 2), 34$ (j3), $26(j 6), 73$ (r3), j4 and $j 5$ not available. Opisthonotum (Fig. 16) with 24 pairs of setae and one supplementary seta or one pair of setae located marginally. Setae length from ca. 24 (some marginal) to $40(\mathrm{~J} 6)$. Dorsal setae simple, podonotum not reticulated, opisthonotum with a scale-like reticulation. Peritreme length 132-144, including stigma (holotype 137), ending anteriorly in the midregion of the opening for Co II, at the level of the podonotal setae $r 2$.

Ventral idiosoma. (Fig. 17) Setae length: 39-44 (st1), 39-46 (st2), 39-42 (st3), 3539 (st4), 33-38 (st5), 38-43 (JV1), 25-27 (ZV1), other opisthogastric setae ca. 33-47, in holotype 41 (st1), 38 (st2), 46 (st3), 42 (st4), 38 (st5), 37 (JV1), 27 (ZV1). Ventral setae simple, reticulation of the opisthogaster scale-like. Anterior margin of the sternal shield (Figs 17, 19D) with a shallow concavity, the area between the presternal plates and the sternum margin with transverse lines. Presternal plates form adaxial protrusions distant similarly to the thickness of the tritosternum. The pores $g v 1$ located axially not far from one another, and close to the posterior margin of the sternum. Paragynial shields (Figs 17, 18A) with metagynial sclerites anteriorly narrow and arcuate. Epigynial shield (Figs 17, 18B,C) with apical part less 


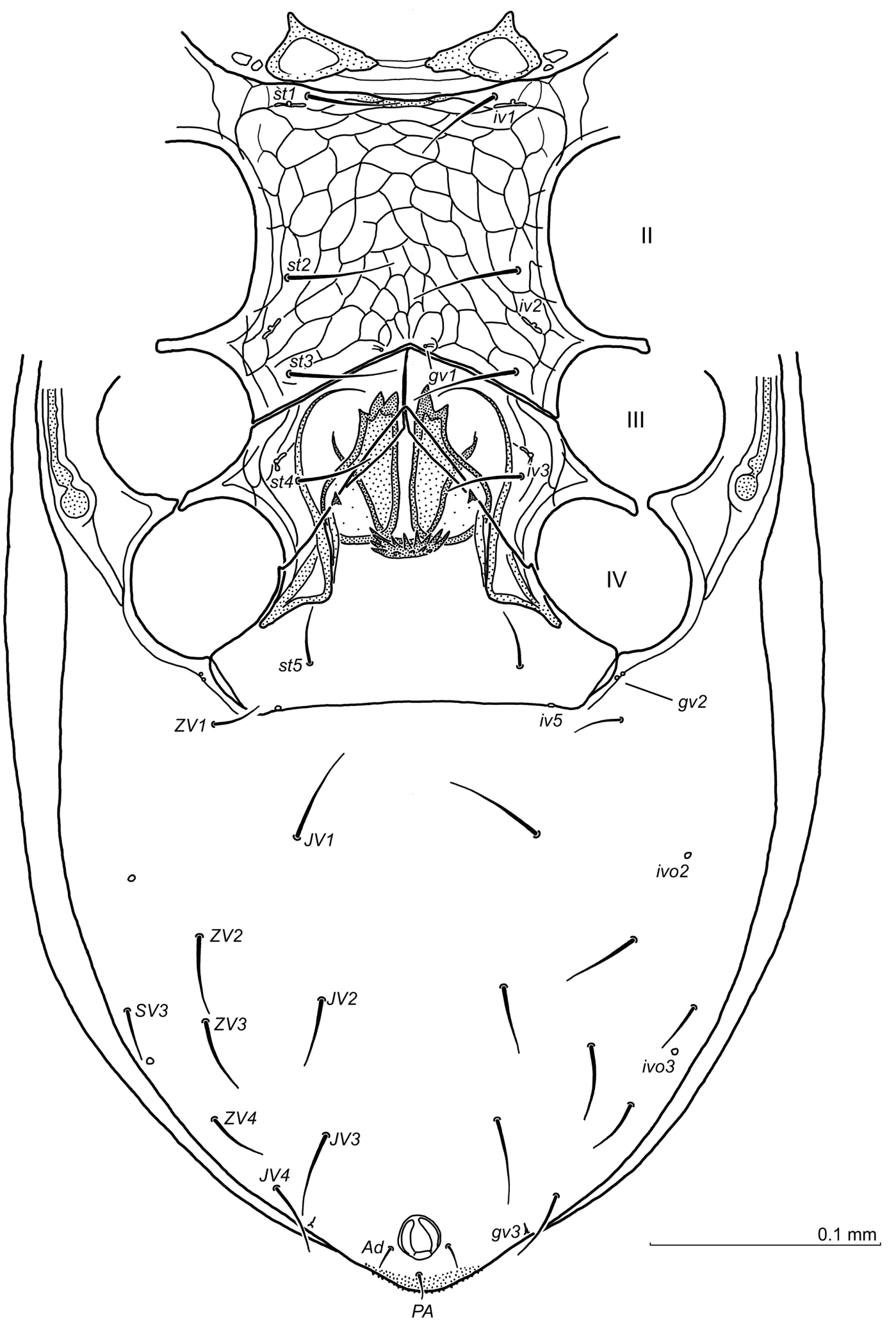

Figure 17 Leptogamasus (L.) parasilvestris n. sp., female: ventral side of idiosoma, holotype. Abbreviations as in Figure 2. 


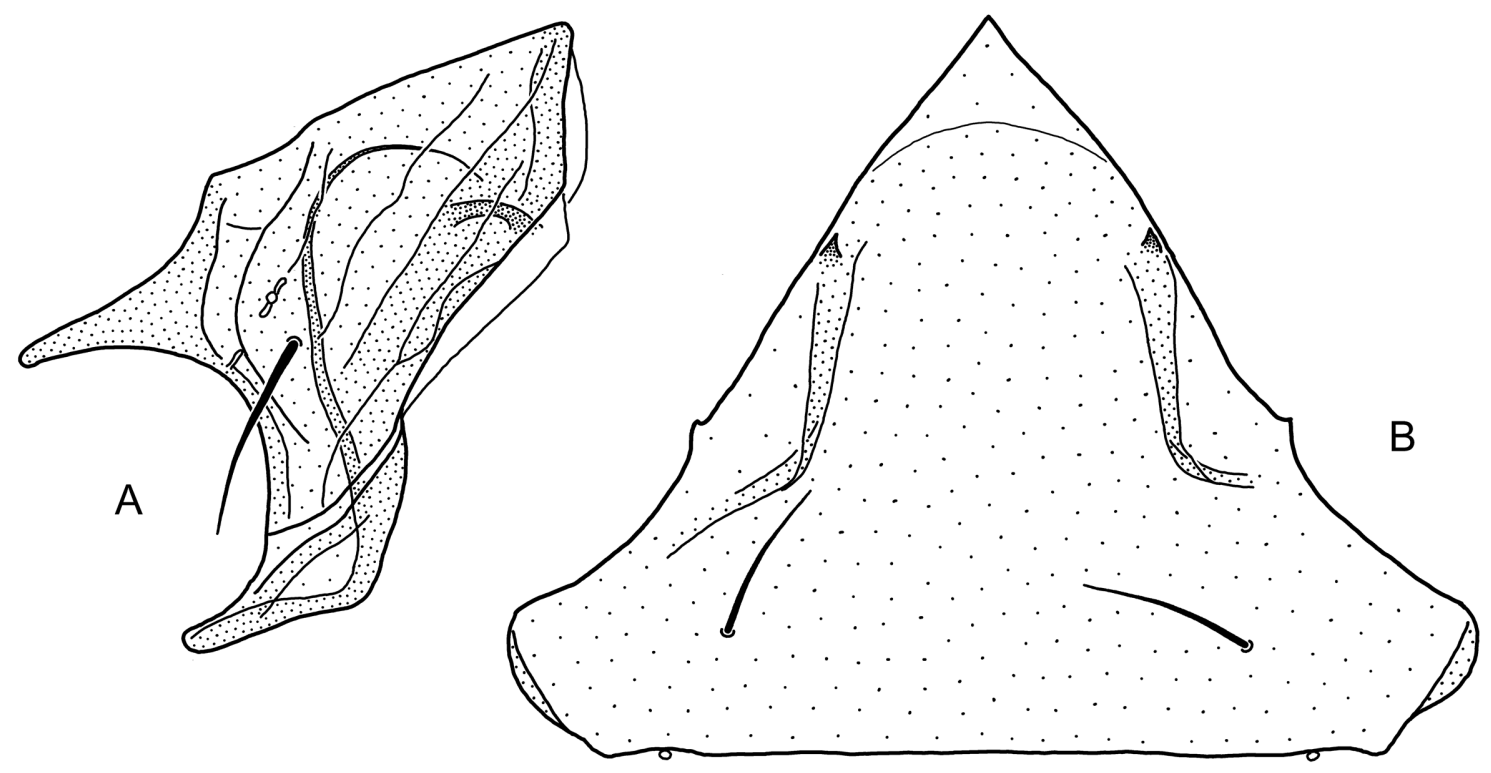

A-G $0.1 \mathrm{~mm}$
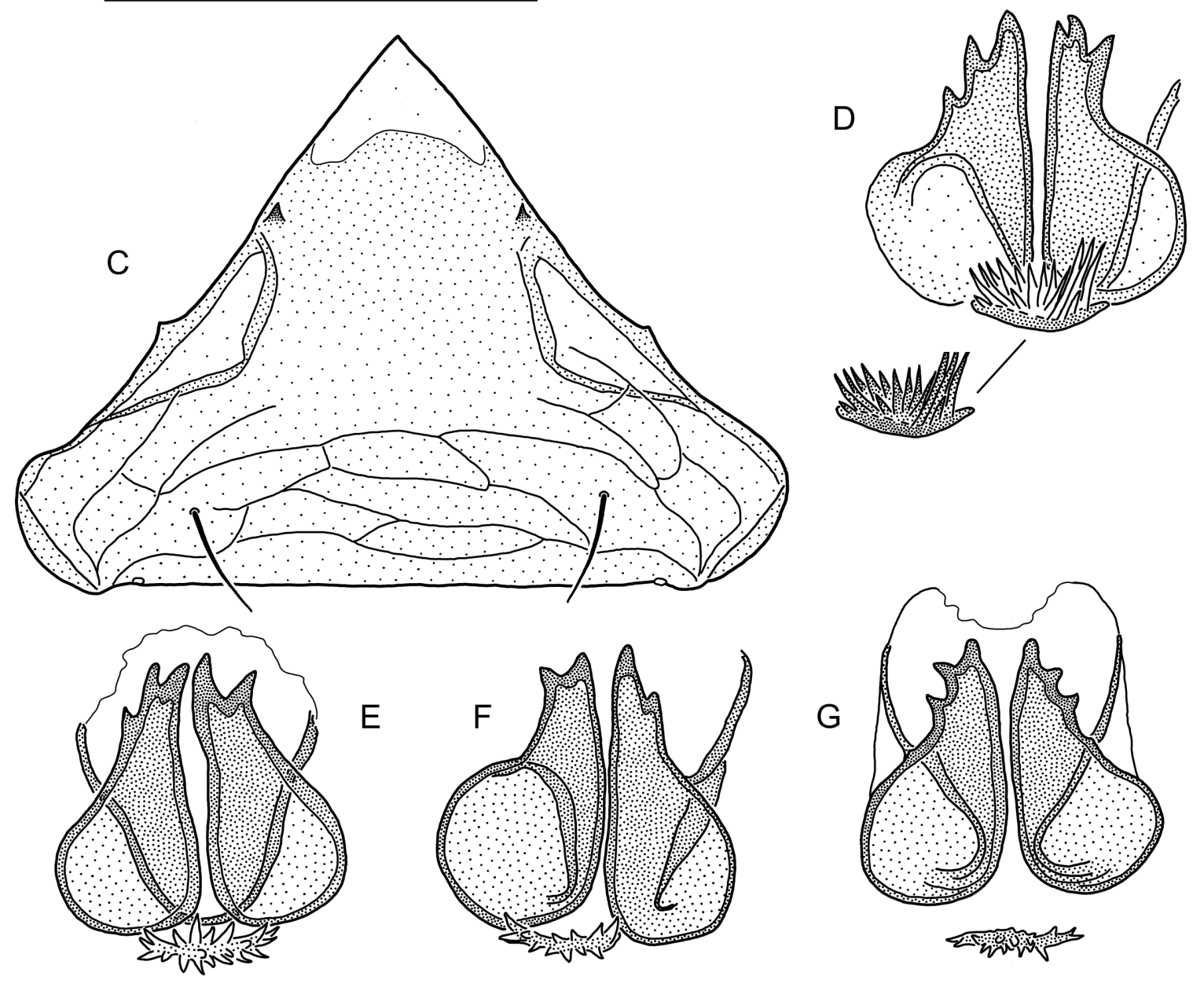

G

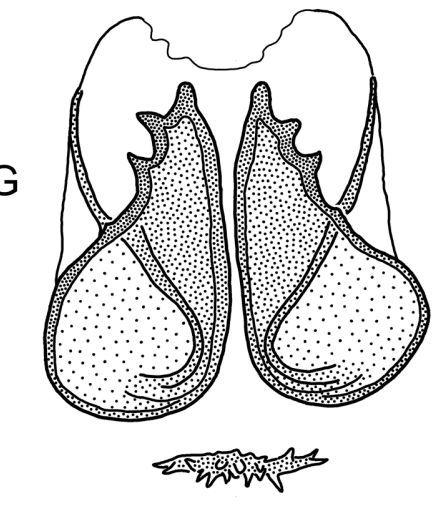

Figure 18 Leptogamasus (L.) parasilvestris n. sp., female: A - paragynium; B, C- epigynium; D-G - endogynium. B, D - holotype. 


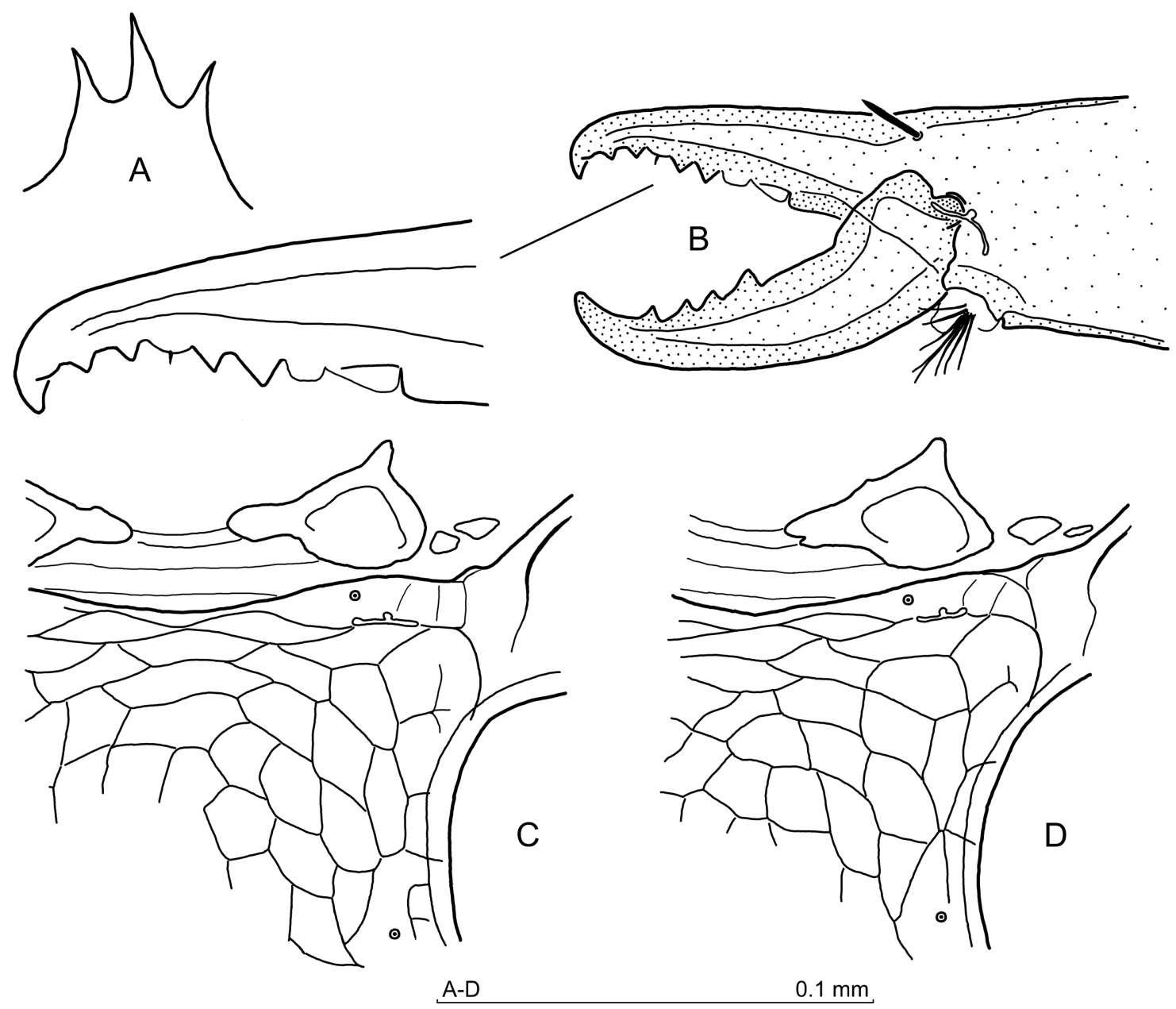

Figure 19 Leptogamasus (L.) parasilvestris n. sp., female: A - gnathotectum; B - chelicera, antiaxially; D - presternal plate and sternal anterior corner. Leptogamasus $($ L. ) silvestris n. sp., female: $\mathrm{C}$ - presternal plate and sternal anterior corner. D - holotype. 
terminally. Leg IV: posterodorsal and posterolateral setae on the femur thicker and shorter, posteroventral setae on the tibia, posterolateral setae on basitarsus and tarsus slightly thickened and terminally barbed. Tr IV without tubercle. Other aspects of legs I-IV unremarkable.

Male (Figures 20, 21)

Idiosoma. Moderately sclerotised, 550-565 x 275-300 (length x width, $\mathrm{n}=5$ ), body oval. Podonotum setae length: 24-27 (j1), 26-31 (j2), 31-37 (j3), 25-30 (j4), 30-37 (j5), 24-26 (j6), 65-71 (r3). Opisthonotum setae length from ca. 21 to 37. Dorsal setae simple. Reticulation of the podonotum non-discernible, opisthonotum with a scale-like reticulation. Peritreme length including stigma 145-155, ending anteriorly as in the females.

Ventral idiosoma - Setae length: 34-38 (st1), 31-35 (st2), 30-33 (st3), 24-26 (st4), 24-26 (st5), 30-33 (JV1), 17-20 (ZV1), other opisthogastric setae ca. 21-35. Ventral setae simple. Sternal region (Fig. 20A) - the anterior margin of genital lamina straight, with minute undulations, the anterior corners rounded. Presternal plates subrectangular, with an arcuate posterior margin. Sternum with gland pores $g v 1$ between $i v 2$ pores and st 3 setae levels, followed by two pairs of thickenings of the sternal cuticle, the anterior ones slightly elongated, the posterior ones button-shaped. Pores gv2 with two distinct openings, pores $i v 5$ halfway between $s t 5$ and $Z V 1$ setae, or somewhat closer to st5. Pores ivo2, ivo3, and gv3 clearly visible.

Gnathosoma. Gnathotectum (Fig. 20B) trispinate, the central prong longer and wider basally. Corniculi (Fig. 20C) with an elevation on the adaxial surface and the thickened antiaxial margins; hypostome with a pair of bean-shaped thickenings at the base of internal malae. Hypostome with 11 rows of denticles, hypostomal and palpcoxal setae simple. Palptrochanter seta $v 1$ simple, $v 2$ barbed (Fig. 20C). Chelicera (Fig. 20D-F) - when observed from the ventral side, mobile digits curved adaxially, slightly shorter than the straight fixed digit. Fixed digit (Fig. 20E) with antiaxial protrusion. Laterally, mobile digit (Fig. 20D) with a single tooth, followed by an arcuate edge proximally; fixed digit narrow and wavy, bearing a small tooth followed by an arcuate lamellar protrusion between the apex and the pilus dentilis; posteriorly to the pilus dentilis the digit ventral edge forms a low, pointed culmination (Fig. 20F).

Legs. Leg II (Fig. 21) spurred as follows: when viewed from the ventral side, the femoral main spur slightly curved, the axillary process directed posterolaterally, the genual and tibial spurs oriented axially, the latter one somewhat longer. From a lateral perspective, the femoral main spur straight, the axillary process half-moon shaped. The spur on the genu roundish, tibial spur conical and more or less pointed, both spurs located at some distance from the distal article margins. Setae on leg II simple, femoral setae al2 and $a d 2$ thicker and shorter, $a d 3$ needle-shaped. Leg IV: trochanter without tooth/tubercle, posterodorsal and posterolateral setae on the femur shorter and thicker, posteroventral seta on the tibia thickened and barbed terminally. Other aspects of legs I-IV unremarkable.

\section{Type material}

Holotype. Female (slide no. 1750 A), Cison di Valmarino, Veneto, northern Italy, $45.9692^{\circ} \mathrm{N}$, $12.1192^{\circ} \mathrm{E}$, alt. ca. $330 \mathrm{~m}$ a.s.1., 30 July 2003, dry litter under deciduous trees. Paratypes. 22 females, 14 males (slides no. 1749, 1750 B-G, 1751), ibid.

Type deposition. The types are deposited in the Zoological Division of the Nature Education Centre, Jagiellonian University, Kraków, Poland.

\section{Etymology}

The specific name parasilvestris is owed to the fact that the species is very similar to $L$. $(L$.) silvestris n. sp., as previously described further above.

\section{Taxonomic remarks}

Two newly described species $L$.(L.) silvestris and L.(L.) parasilvestris are very similar and differ only in some morphological aspects. Their key discriminating features are as follows. In the females, the epigynial shield is either smooth on the dorsal side (L.(L.) silvestris), or features 

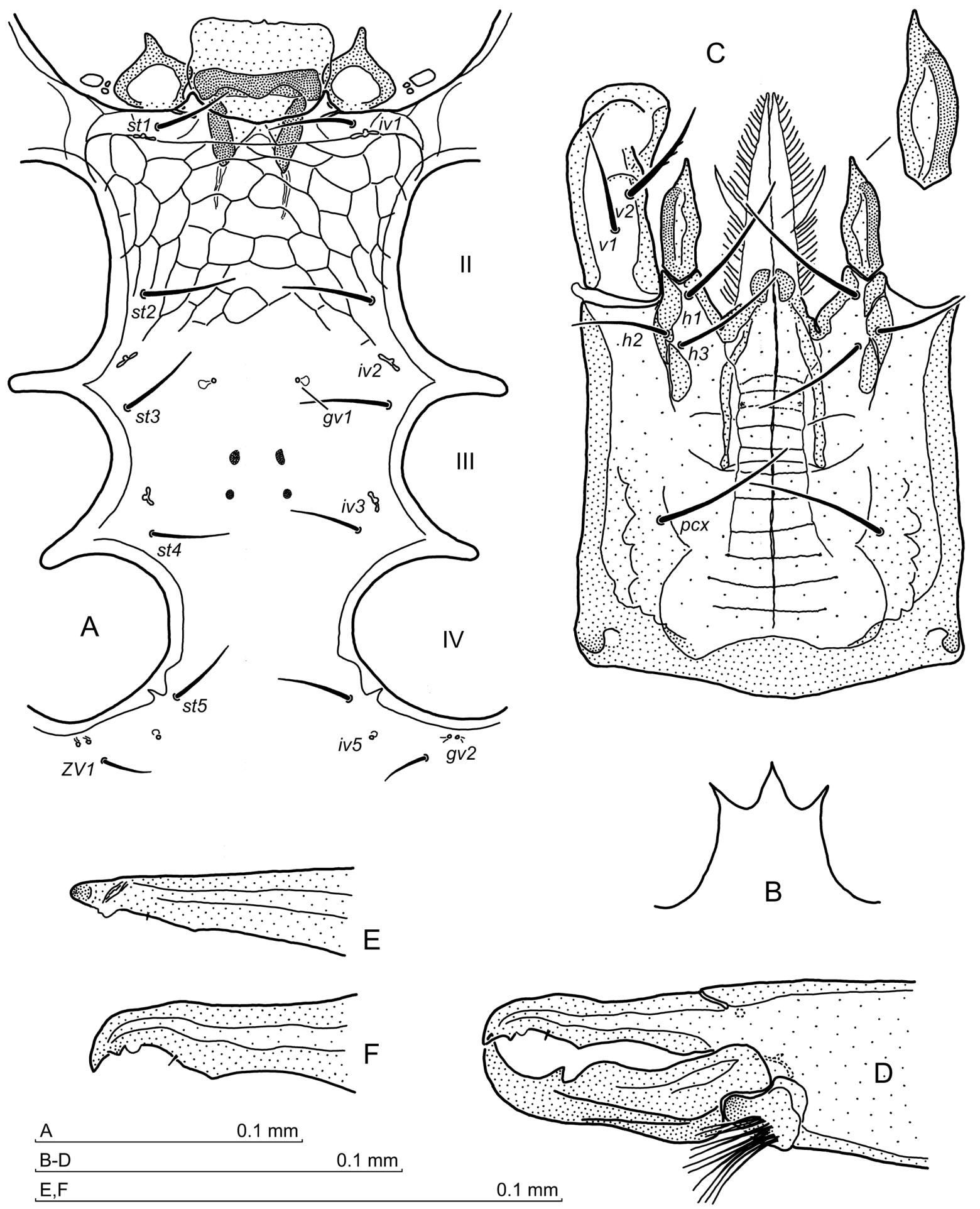

Figure 20 Leptogamasus (L.) parasilvestris n. sp., male: A - presternal plates, genital lamina and sternogenital shield; B - gnathotectum; C - gnathosoma, ventrally, note the thickenings at the base of the internal malae; D - chelicera, adaxially; E - cheliceral fixed digit in an oblique view; cheliceral fixed digit in a lateral view. Abbreviations as in Figure 4. 


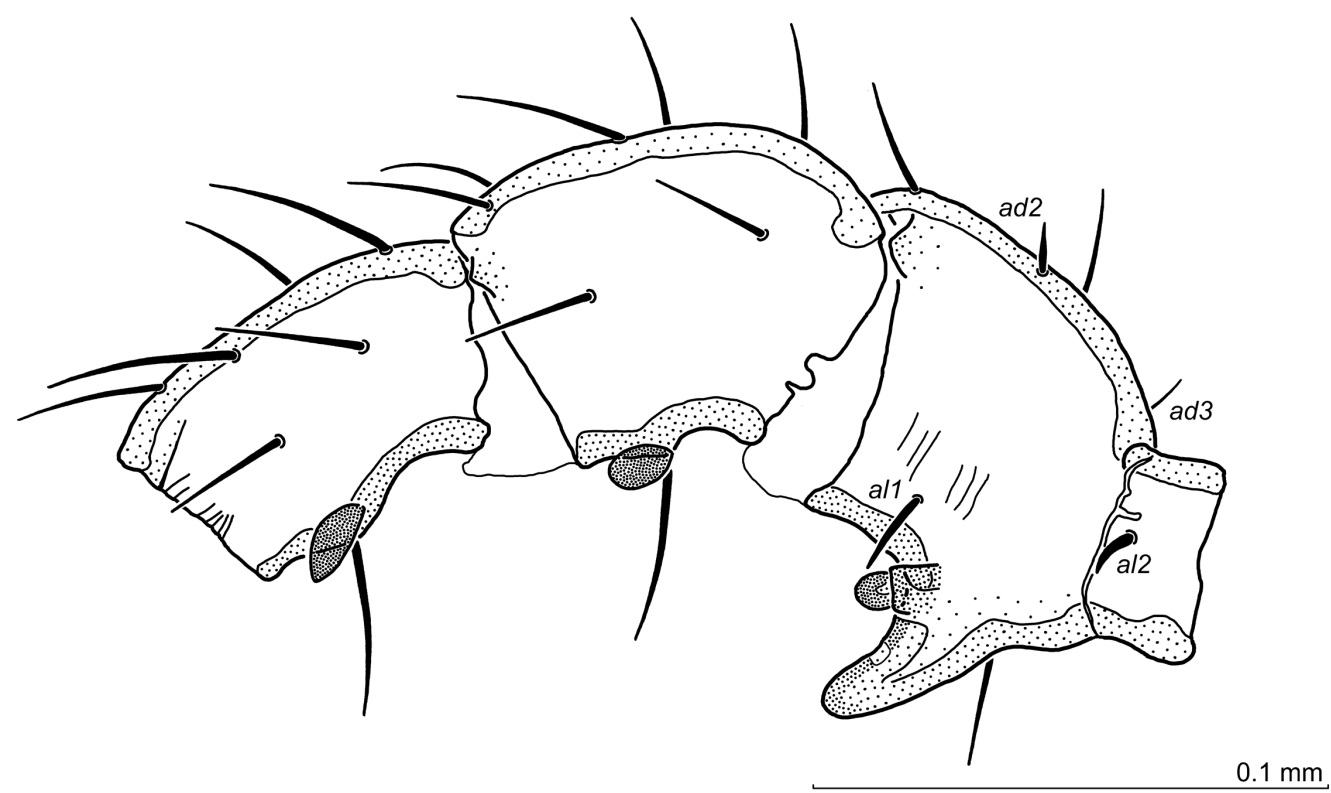

Figure 21 Leptogamasus (L.) parasilvestris n. sp., male: Fe II, Ge II and Ti II, anterolaterally. Some setae are marked.

2 tiny teeth located near the epigynium margin (L.(L.) parasilvestris) . In L.(L.) silvestris, the endogynial spherules are straight, or only slightly concave laterally, in L.(L.) parasilvestris their lateral margins are deeply concave. Stipule is short in L.(L.) silvestris, but evidently longer in L.(L.) parasilvestris. In the males, the posterior pair of sternal thickenings at $i v 3$ level is small in L.(L.) silvestris and larger in the other species. More distinct differences are hypostome and the fixed digit of chelicera: in L.(L.) parasilvestris the hypostome shows a pair of bean-shaped thickening at the base of internal malae, which in L.(L.) silvestris is absent, the cheliceral fixed digit is wavy in the former species, but straight in the latter. The remaining characteristics are less distinct and may vary.

\section{Leptogamasus (Leptogamasus) monteamiatus n. sp.}

Zoobank: 5A07F640-891F-4843-A5B9-D99BDD8A47B0

(Figures 22-26)

\section{Diagnosis}

Female and male. Gnathotectum trispinate with pointed, similar prongs, in the male shorter; gland pore $g v 1$ present; podonotum with 21 pairs of setae, opisthonotum with 24 pairs of setae, plus 1 or 2 supplementary setae located marginally; Tr IV without tubercle.

Female. Presternal plates subtriangular with posterior margin arcuate; sternal shield anterior margin concave; gland pores $g v l$ close to central axis of the sternum and posterior sternal margin; epigynial shield with less pigmented band subapically, the anterior margins straight, posterolateral margins arcuate, the internal (dorsal) surface with two distinct teeth; spherules of the endogynium distant, each one forming anteriorly an acute pyramidal protrusion, accompanied by the less prominent tooth or tooth-like protrusion; stipule long but narrow, richly dentate, usually ventrally oriented and bearing large lateral teeth. 


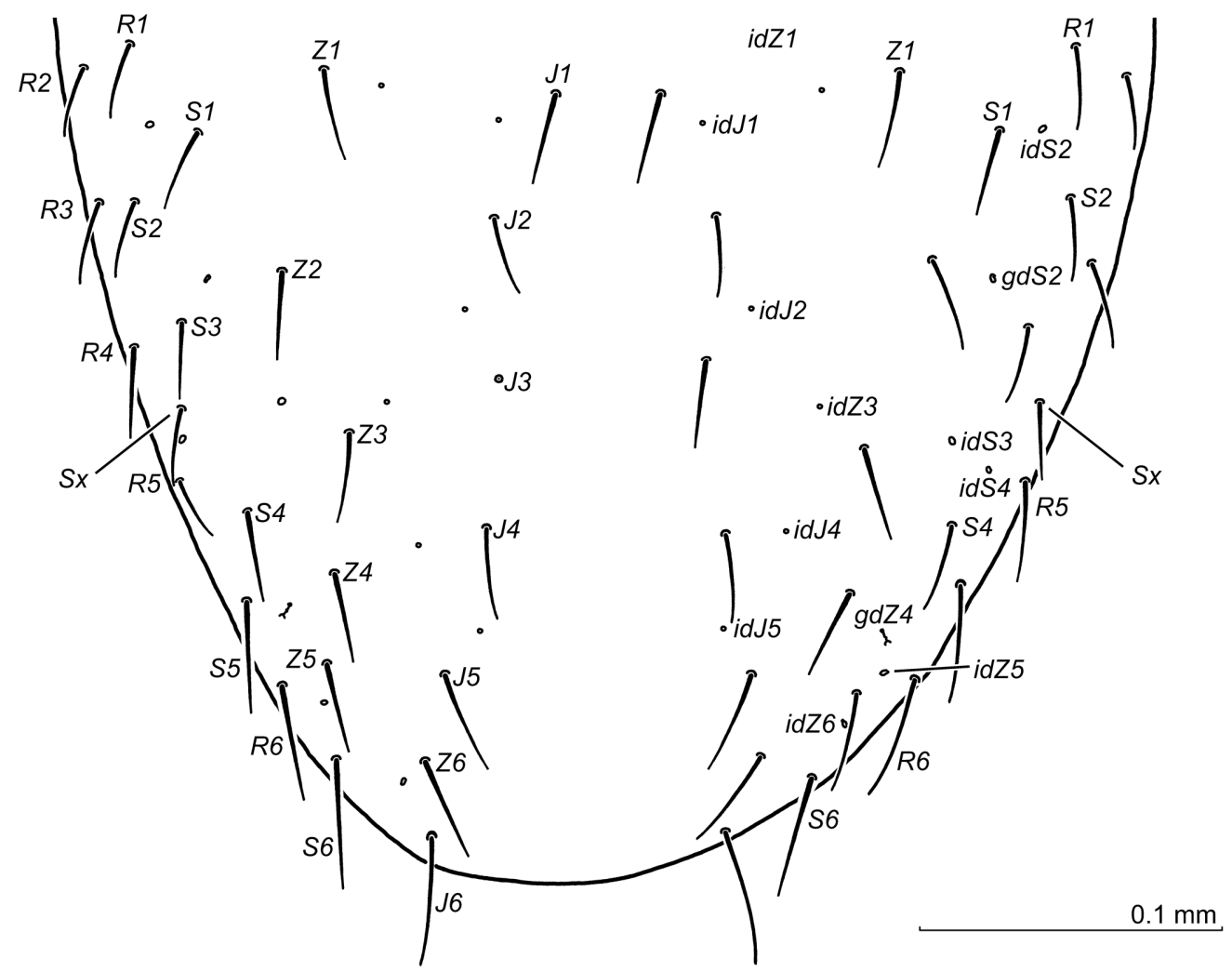

Figure 22 Leptogamasus (L.) monteamiatus n. sp., opisthonotum of the female, holotype.

Male. Genital lamina with concave anterior margin and rounded corners; presternal plates subrectangular; corniculi with an elevation on the adaxial margin; cheliceral fixed digit featuring arcuate lamellar protrusion in front of the pilus dentilis and a row of ca. 8-9 small teeth behind it; leg II in the ventral view: femoral main spur, as well as the genual and tibial ones oriented axially; leg II in the lateral view: femoral main spur straight, axillary process semilunar to finger-shaped, spurs on the genu and tibia conical, located farther from (tibial spur) or closer (genual one) to the distal article margin.

\section{Description}

Female (Figures 22-24)

Idiosoma. Moderately sclerotised, 585-620 x 335-360 (length $x$ width, $n=5$ ), holotype 623 x 346. Podonotum with 21 pairs of setae, setae length: 34-39 (j1), 43-46 (j2), 43-50 (j3), 41-48 (j4), 34-37 (j5), 27-30 (j6), 80-92 (r3), in holotype 40 (j1), 43 (j2), 48 (j4), 38 (j5), $30(j 6), 88(r 3), j 3$ broken. Opisthonotum (Fig. 15) with 24-26 pairs of setae: 24 pairs of setae, plus one or two supplementary pairs of setae located marginally. Setae length from ca. 23 to 50 , holotype $22-48$, the longest J6. Dorsal setae simple, reticulation of the podonotum poorly discernible, opisthonotum with a scale-like reticulation. Peritreme length 150-157, including stigma (holotype 154), reaching the anterior region of the opening for Co II, ending just anteriorly to the podonotal seta $r 2$.

Ventral idiosoma. (Fig. 23) Setae length: 38-42 (st1), 43-51 (st2), 46-50 (st3), 33-38 (st4), 34-42 (st5), 39-41 (JV1), 27-31 (ZV1), other opisthogastric setae ca. 24-39, in holotype 


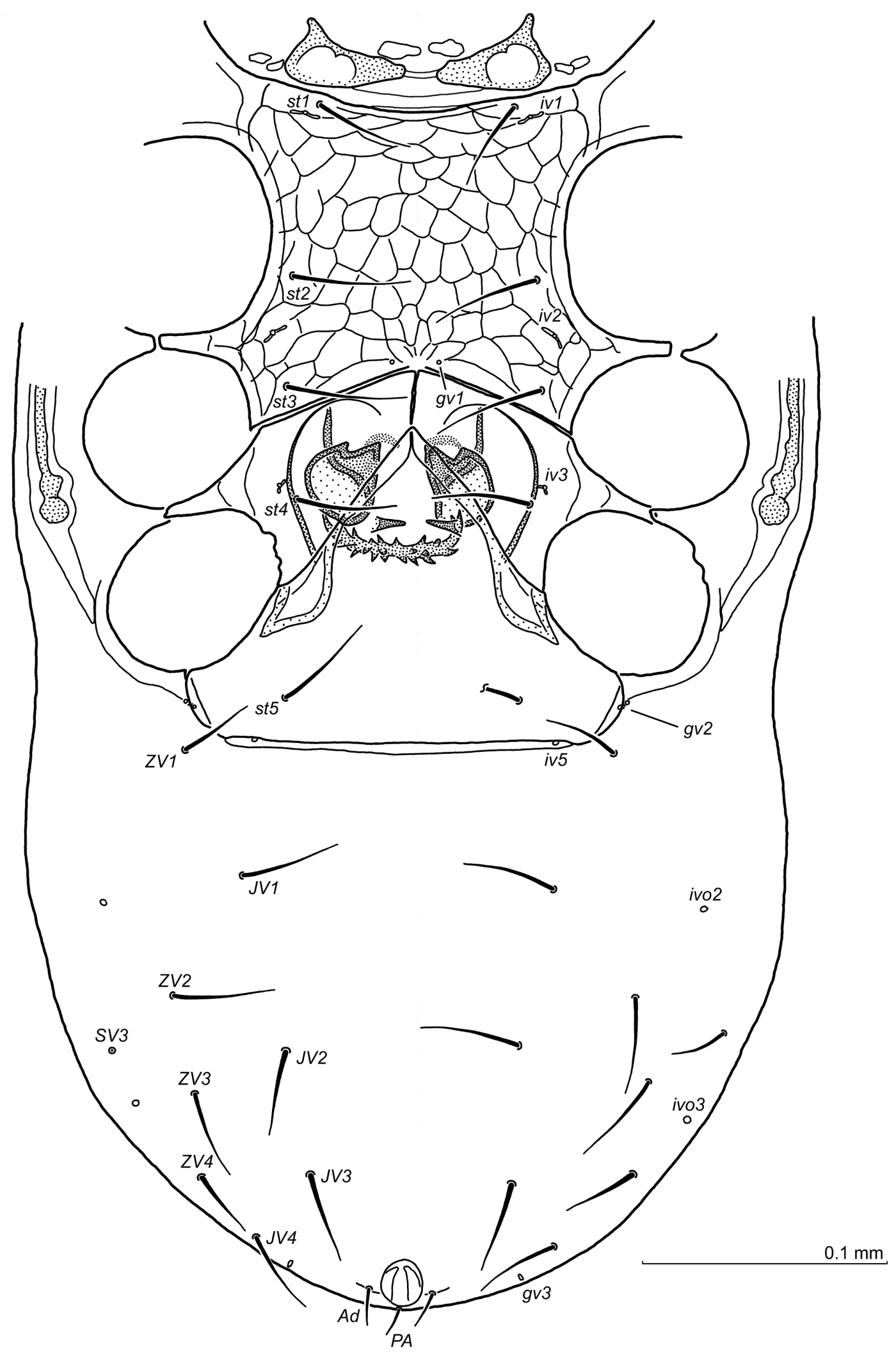

Figure 23 Leptogamasus (L.) monteamiatus n. sp., female: ventral side of idiosoma, holotype. Abbreviations as in Figure 2. 

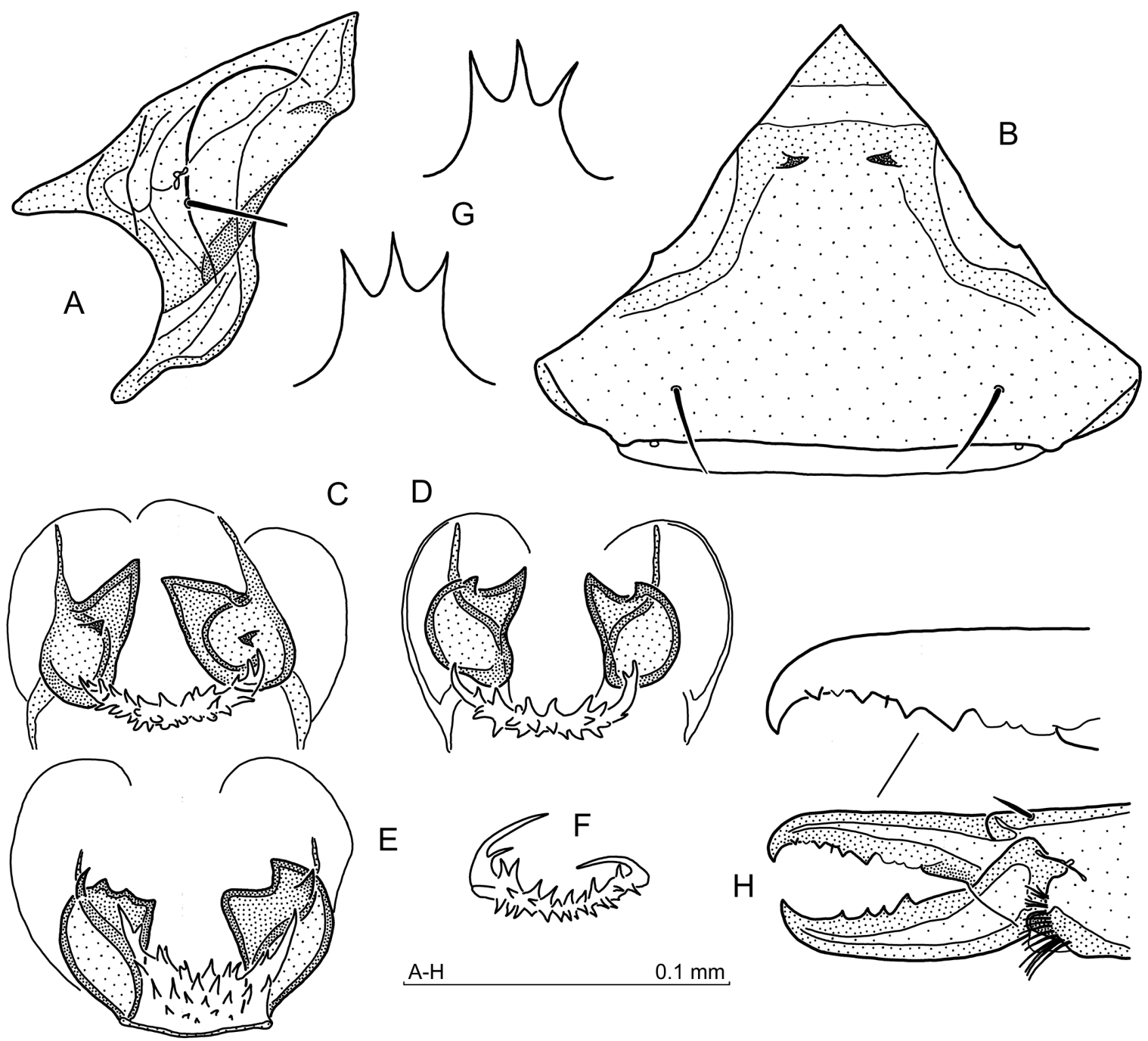

A-H $0.1 \mathrm{~mm}$

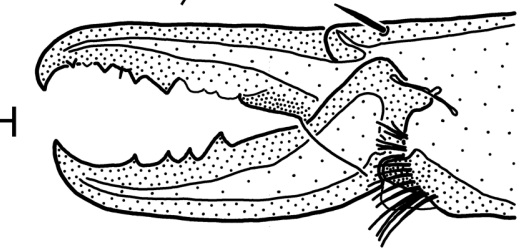

Figure 24 Leptogamasus (L.) monteamiatus n. sp., female: A - paragynium; B - epigynium; C-E-endogynium; F - stipule; G-gnathotectum, two aspects; $\mathrm{H}$ - chelicera, antiaxially. D - holotype.

41 (st1), 50 (st2), 50 (st3), 39 (st4), 42 (st5), 42 (JV1), 29 (ZV1), other opisthogastric setae ca. 25-39. Ventral setae simple, reticulation of the sternum and opisthogaster scale-like. Presternal plates (Fig. 23) at the distance similar to the tritosternum thickness, their posterior margins convex. Anterior margin of the sternal shield concave, space between the sternum and the presternal plates with lines. Sternal pores $g v 1$ located axially in close proximity of the posterior sternal margin. Paragynial shields (Figs 23, 24A) with the metagynial sclerites narrow and arcuate. Epigynial shield (Figs 23, 24B) with the anterior margins straight, posterolateral margins arcuate, the posterior one slightly concave, forming a distinct soft cuticular band between the epigynium and the opisthogaster. Subapically, the epigynium shows less pigmented band, followed by two distinct teeth on the epigynial internal (dorsal) surface. Endogynium (Figs 23, 24C-F) with rather distant spherules, each one with anterior acute pyramidal protrusion, accompanied laterally or ventrally by the less prominent tooth or tooth-like protrusion; stipule long and narrow, richly dentate, usually ventrally oriented, and 
boasting large lateral teeth. Gland pores gv2 (Fig. 23) with double channels; iv5, ivo2, ivo3 and gv3 clearly visible.

Gnathosoma. Gnathotectum (Fig. 24G) trispinate, all prongs acute and moderately long, the central one somewhat longer. Corniculi conical, hypostome with ca. 11 rows of denticles, hypostomal and palpcoxal setae simple. Palptrochanter seta $v 1$ simple, $v 2$ barbed. Chelicera (Fig. 24H) - movable digit with four teeth, the proximal one the largest, fixed digit with two distant teeth separated by a tiny lamellar one in front of the pilus dentilis, and two teeth followed by a lamellar edge behind the pilus dentilis.

Legs. Setae $a l$ on Tr I somewhat shorter and thicker. Leg II: Fe anterolateral setae al1, al2 and anterodorsal (ad2) seta shorter and thicker, anteroventral seta on Fe II larger and barbed, anteroventral setae on Ge II and Ti II somewhat thicker and finely barbed. Leg IV: posterodorsal and posterolateral setae on the femur thicker and shorter, posteroventral setae on the genu and tibia, as well as the posterolateral setae on the basitarsus and tarsus thickened and terminally barbed. Tr IV without tubercle. Other aspects of legs I-IV unremarkable.

Male (Figures 25, 26)

Idiosoma. Sclerotised as in the female, 560-575 x 280-305 (length x width, $\mathrm{n}=5$ ), body with very shallow lateral incisions at Co IV level. Podonotum setae length: 33-37 (j1), 30-35 (j2), 36-42 (j3), 37-42 (j4), 28-31 (j5), 27-30 (j6), 79-84 (r3). Opisthonotum setae length from ca. 22 to 42 . Peritreme length including stigma 146-153, ending anteriorly, as in the females. Dorsal setae simple.

Ventral idiosoma. Setae length: 37-41 (st1), 38-42 (st2), 33-38 (st3), 30-37 (st4), 26-30 (st5), 35-39 (JV1), 21-27 (ZV1), other opisthogastric setae ca. 22-45. Ventral setae simple. Sternal region (Fig. 25A) genital lamina with the rounded corners and shallow concavity of the anterior edge. Presternal plates subrectangular. Sternum with gland pores $g v 1$ slightly anteriorly to the $s t 3$ setae level, followed by two elongated, moderately pronounced thickenings of the sternal cuticle, and two more pronounced thickenings at the $i v 3$ level. Pores $g v 2$ with distinct and distant two channels, pore $i v 5$ halfway between st 5 and $Z V 1$ setae or somewhat closer to st 5 seta. Sternum, opisthogaster and opisthonotum reticulation scale-like, sometimes less at $i v 3$ pores level (Fig. 25A).

Gnathosoma. Gnathotectum (Fig. 25B) trispinate, central prong somewhat longer. Corniculi (Fig. 25C) with an elevation on the adaxial margin, hypostome with ca. 11 rows of denticles, hypostomal and palpcoxal setae simple. Palptrochanter seta $v 1$ simple, $v 2$ barbed. Chelicera - when observed from the ventral side, the mobile digits nearly straight, and the fixed digits straight. Laterally (Fig. 25D), movable digit with a single tooth, followed by a sinuous edge proximally, fixed digit straight, featuring an arcuate lamellar protrusion in front of the pilus dentilis, and a row of ca. 8-9 small teeth behind it.

Legs. Leg II (Fig. 26A-C) spurred as follows: when viewed from the ventral side (Fig. 26A,B), the femoral main spur, as well as the genual and tibial ones, are oriented axially. When leg II is viewed from the lateral perspective (Fig. 26C), the main spur is straight, the axillary process semilunar to finger-shaped, the genual and tibial spurs are conical, located farther from (tibial spur) or closer (genual one) to the distal article margin. Setae on leg II simple, setae all, $a l 2$ and $a d 2$ on the femur short and thicker, $a d 1$ normal, $a d 3$ needle-like. Seta $a l$ on Tr I short and thick, leg IV setation as in the female. Tubercle on Tr IV absent. Other aspects of legs I-IV unremarkable.

\section{Type material}

Holotype Female (slide no. 1919 A), Monte Amiata, Tuscany, Italy, $42.8842^{\circ} \mathrm{N}, 11.6572^{\circ} \mathrm{E}$, alt. ca. $950 \mathrm{~m}$ a.s.1., 17 Sept. 2004, chestnut woodland litter. Paratypes 24 females, 17 males (slides no. 1854, 1858, 1917, 1919 A-J, 1921), ibid. All the material collected by the author and M. Skorupski.

Type deposition. The types are deposited in the Zoological Division of the Nature Education Centre, Jagiellonian University, Kraków, Poland. 

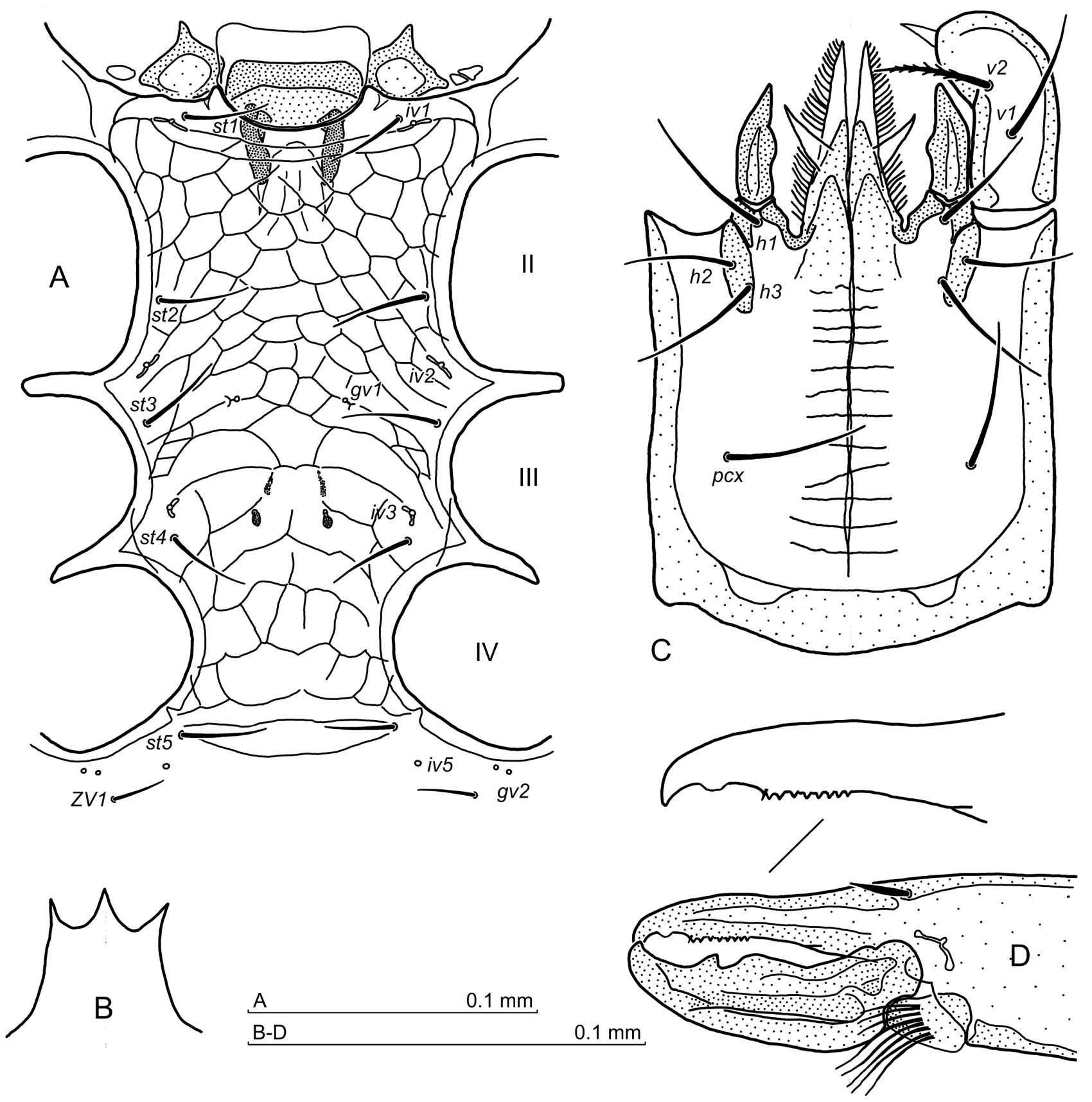

Figure 25 Leptogamasus (L.) monteamiatus n. sp., male: A - presternal plates, genital lamina and sternogenital shield; B - gnathotectum; C -gnathosoma, ventrally; D - chelicera, antiaxially. Abbreviations as in Figure 4. 

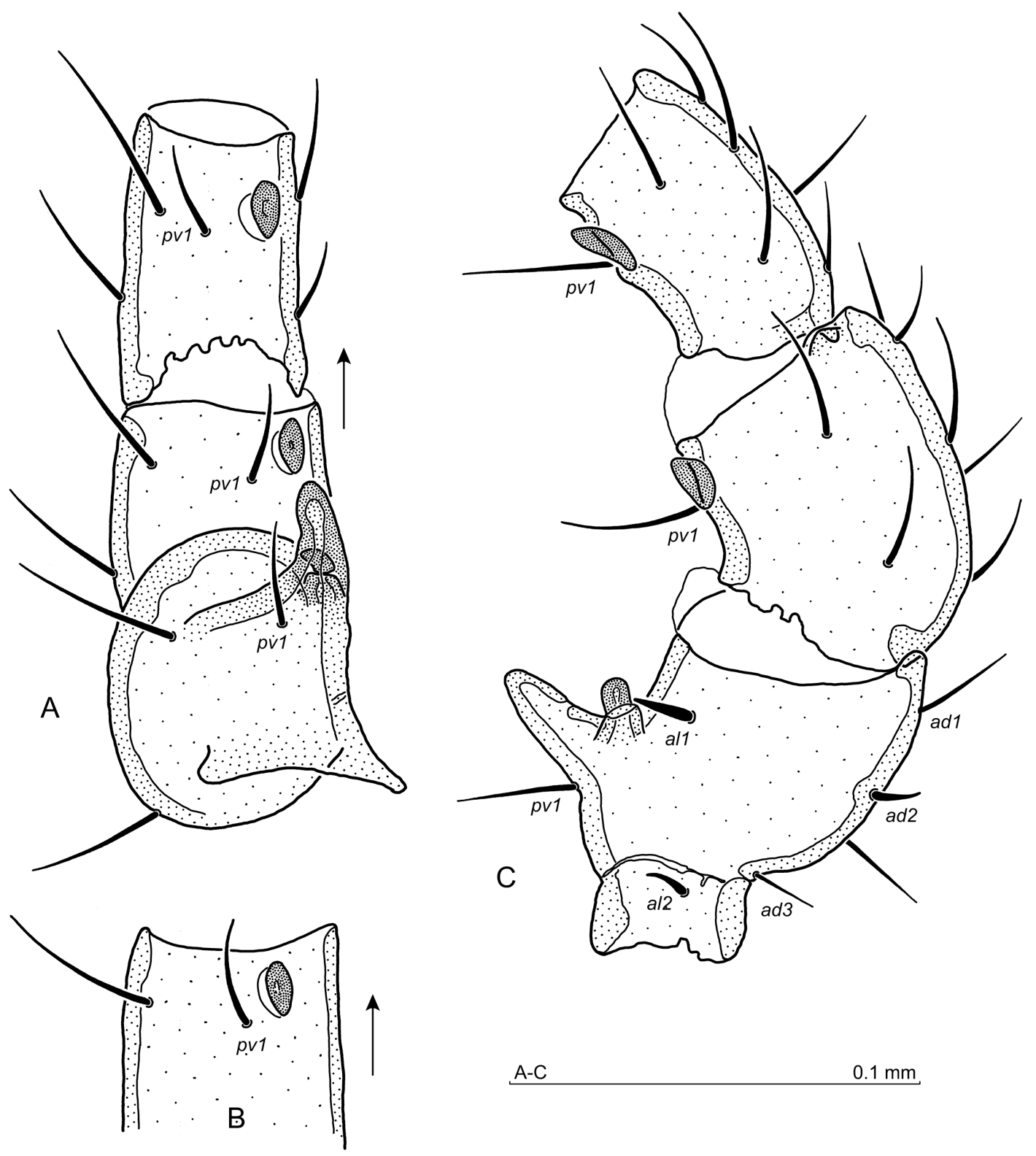

Figure 26 Leptogamasus (L.) monteamiatus n. sp., male: A - Fe II, Ge II and Ti II, ventrally; B - Ge II, other aspect of the spur location; C Fe II, Ge II and Ti II in the anterolateral perspective. Some setae are marked. Arrows at the anterolateral side.

\section{Etymology}

The specific name refers to Monte Amiata, a mountain of volcanic origin located in central Italy where the material had been encountered and collected.

\section{Differential taxonomy}

The currently described new species of Leptogamasus (Leptogamasus) show very unusual characteristics not encountered in any previously acknowledged species. As far as the females 
are concerned, L. (L.) bucerus, L. (L.) cortinis, and L. (L.) monteamiatus possess a pair of distinct teeth on the internal (dorsal) surface of the epigynial shield. Leptogamasus (L.) bucerus may be compared with Leptogamasus (L.) alstoni (Bhattacharyya, 1963), Leptogamasus (L.) variabilis Juvara-Bals, 1981, Leptogamasus (L.) varpulus (Athias-Henriot, 1967) and Leptogamasus (L.) margaretae Juvara-Bals, 1981. All these species show the spherules axially elongated and pointed anteriorly, although the stipule in $L$. (L.) bucerus is long and forked, in $L$. (L.) varpulus and $L$. (L.) margaretae it is rectangular in outline, and in $L$. (L.) alstoni, as well as in $L$. (L.) variabilis the stipule is short and wide. Besides, in the new species under study the spherules are pointed anteriorly and do not bear any teeth or denticles, in $L$. (L.) varpulus, the tips of the spherules are finely dentate. On the other hand, in L. (L.) alstoni, L. (L.) margaretae and $L$. (L.) variabilis there are one or two pairs of small teeth on the spherular surface. The male of $L$. (L.) bucerus is identifiable in view of a very characteristic cheliceral fixed digit, widened apically in fan form, and elevated on the dorsal margin. Such cheliceral fixed digit is not encountered in any other known species.

The female of $L$. (L.) cortinis shows some similarities with $L$. (L.) margaretae and $L$. $(L$. variabilis, but differs with them in terms of the actual location of the epigynial teeth - in $L$. $(L$.) cortinis they are located more posteriorly, as well as the shape of endogynial stipule is different. Besides, in $L$. (L.) margaretae, the anterior part of the endogynial sac wall bears two pairs of teeth and a single tooth located axially, the endogynial teeth in $L$. (L.) cortinis have different location and form, and the axial tooth is absent. The male of $L$. (L.) cortinis differs from the males of $L$. (L.) margaretae and $L$. (L.) variabilis, mainly owing to the chelicera structure, i.e. the movable digit is narrow, wavy and obliquely cut apically, the fixed digit is narrow, straight and edentate behind the pilus dentilis. Furthermore, it shows a peculiar tubercle on the external (upper) margin. Such cheliceral structure is not encountered in $L$. (L.) margaretae and $L$. (L.) variabilis. The male of $L$. (L.) cortinis shows also an additional peculiarity, i.e. a tubercle on the ventral side of corniculus, the feature observed in Leptogamasus (L.) orghidani Juvara-Bals, 1981. Both the chelicera structure in L. (L.) orghidani male, and the endogynium form in the female are distinctly different than those encountered in $L$. (L.) cortinis.

The female of Leptogamasus (L.) monteamiatus is similar to L. (L.) alstoni, owing to the endogynium structure, but in the latter species the spherules are relatively larger, and the stipule has different shape. Some additional teeth, possibly in the endogynial sac, may also be encountered in L. (L.) alstoni but not in L. (L.) monteamiatus. Originally, Bhattacharyya (1963) described the female, and the male was described by Karg (1971). The male has a relatively long and narrow cheliceral digits, and the fixed digit is edentate behind the pilus dentilis, in $L$. (L.) monteamiatus it bears a row of 8-9 small teeth. Leptogamasus (L.) parasilvestris female is characterised by two tiny teeth on the dorsal side of the epigynial shield, located marginally. The teeth similar to a certain extent may be encountered in Leptogamasus (L.) belligerens Witaliński, 1973, but other features do not match. Especially, the endogynial stipule in $L$. $(L$.) belligerens is double and lamellar, in L. (L.) parasilvestris is single and solid. Also the shape of the spherule is completely different. The main difference between the males in the two species under study consists in the cheliceral fixed digit: in $L$. (L.) parasilvestris with edentate edge behind the pilus dentilis, featuring numerous small teeth in $L$. (L.) belligerens.

The epigynial shield in $L$. (L.) silvestris female does not bear any teeth on the dorsal surface. The shape of the endogynial spherules is very characteristic and not encountered in any other Leptogamasus species, except for the newly described $L$. (L.) parasilvestris (see the taxonomic remarks further above). In Leptogamasus (L.) paracarpaticus Juvara-Bals, 1981, the spherules are slightly convergent anteriorly, and the short stipule is located between their posterior ends, but the anterior poles of the spherules are rounded, not boasting several teeth, as in the $L$. ( $L$.) silvestris The males in both species differ in respect of leg II armature, i.e. the femoral main spur is more stout in $L$. (L.) paracarpaticus, as opposed to $L$. (L.) silvestris, and the genual spur is conical rather than tuberculate, as in the latter species. 


\section{Acknowledgements}

The study was partly supported by a grant allocated by the Jagiellonian University, Kraków, Poland (Grant Ref. No K/ZDS/008060).

\section{References}

Athias-Henriot, C. 1967. Observations sur les Pergamasus. I. Sous-genre Paragamasus Hull, 1918 (Zoologie Acariens anactinotriches, Parasitidae). Mém. Mus. natl. Hist. nat., Sér. A (Zool.), 49: 1-197.

Bhattacharyya, S. K. 1963. A revision of the British mites of the genus Pergamasus Berlese s. lat. (Acari: Mesostigmata). Bull. Br. Mus. Nat. Hist. (Zool.), 11: 131-242. https://doi.org/10.5962/bhl.part.4717

Juvara-Balş, I. 1981. Nouvelle définition du genre Leptogamasus Trägårdh, 1936 (Acarina, Gamasida, Parasitidae) et description de six nouvelles espèces. Revue Suisse Zool., 88: 77-93. https://doi.org/10. 5962/bhl.part.82355

Karg, W. 1971. Acari (Acarina), Milben Unterordnung Anactinochaeta (Parasitiformes). Die freilebenden Gamasina (Gamasides), Raubmilben. Tierwelt Deutschlands, 59: 475 pp. https://doi.org/10.1002/mmnd. 4820300510

Trägårdh, I. 1936. Leptogamasus, a new genus of Acari from Sweden. Ent. Tidskr., 57: 227-234.

Witaliński, W. 1973. New species of the genus Leptogamasus Trägårdh, 1936, sensu Athias-Henriot, 1971 (Acarina, Parasitidae). Acta Zool. Cracov., 18: 271-300.

Witaliński, W. 2019. Five new species of mites in the genus Leptogamasus Trägårdh, 1936, and a new subgenus Medioperigamasus (Parasitiformes: Parasitidae). Zootaxa, 4619: 487-517. https://doi.org/10.11646/zootaxa.4619.3.4

Witaliński, W. 2020. New Leptogamasus mite species (Parasitiformes: Parasitidae) from Europe. I. Poland. Acarologia, 60: 698-721. https://doi.org/10.24349/acarologia/20204397

Witaliński, W. 2021. New Leptogamasus mite species (Parasitiformes: Parasitidae) from Europe. II. Northern Italy. Acarologia, 61: 173-200. https://doi.org/10.24349/acarologia/20214425 